\title{
Zirconium, calcium, and strontium contents in magnesium based biodegradable alloys modulate the efficiency of implant-induced osseointegration
}

This article was published in the following Dove Press journal:

International Journal of Nanomedicine

8 August 2013

Number of times this article has been viewed

\author{
Dolly Mushahary ${ }^{1,2}$ \\ Ragamouni Sravanthi ${ }^{2}$ \\ Yuncang $\mathrm{Li}^{2}$ \\ Mahesh J Kumar' \\ Nemani Harishankar ${ }^{4}$ \\ Peter D Hodgson' \\ Cuie Wen ${ }^{3}$ \\ Gopal Pande ${ }^{2}$
}

'Institute for Frontier Materials, Deakin University, Geelong, Australia; ${ }^{2}$ CSIR- Centre for Cellular and Molecular Biology, Hyderabad, India; ${ }^{3}$ Faculty of Engineering and Industrial Sciences, Swinburne University of Technology, Hawthorn, Australia; ${ }^{4}$ National Institute of Nutrition (ICMR), Tarnaka, Hyderabad, India
Correspondence: Gopal Pande CSIR - Centre for Cellular and Molecular Biology, Uppal Road, Hyderabad 500 007,

Andhra Pradesh, India

Tel +9| $4027 \mid 92605$

$\mathrm{Fax}+914027160591$

Email gpande@ccmb.res.in

\begin{abstract}
Development of new biodegradable implants and devices is necessary to meet the increasing needs of regenerative orthopedic procedures. An important consideration while formulating new implant materials is that they should physicochemically and biologically mimic bone-like properties. In earlier studies, we have developed and characterized magnesium based biodegradable alloys, in particular magnesium-zirconium ( $\mathrm{Mg}-\mathrm{Zr}$ ) alloys. Here we have reported the biological properties of four $\mathrm{Mg}-\mathrm{Zr}$ alloys containing different quantities of strontium or calcium. The alloys were implanted in small cavities made in femur bones of New Zealand White rabbits, and the quantitative and qualitative assessments of newly induced bone tissue were carried out. A total of 30 experimental animals, three for each implant type, were studied, and bone induction was assessed by histological, immunohistochemical and radiological methods; cavities in the femurs with no implants and observed for the same period of time were kept as controls. Our results showed that $\mathrm{Mg}-\mathrm{Zr}$ alloys containing appropriate quantities of strontium were more efficient in inducing good quality mineralized bone than other alloys. Our results have been discussed in the context of physicochemical and biological properties of the alloys, and they could be very useful in determining the nature of future generations of biodegradable orthopedic implants.
\end{abstract}

Keywords: osteoblasts, bone mineralization, corrosion, osseointegration, surface energy, peri-implant

\section{Introduction}

Because of their varied attractive properties, many metals and their alloys have been considered as biomedical implants. The idea of biodegradable alloys initiated with the necessity for secondary surgery for removal of the implanted material and their unsuitability in load bearing applications. A number of magnesium $(\mathrm{Mg})$ based alloys, prepared with alloying elements from the same group of the periodic table, have been reported for dental replacements and orthopedic applications. ${ }^{1-3} \mathrm{Mg}$ enriched materials have been studied as oral implants ${ }^{4}$ and as filler materials in extracted sockets ${ }^{5}$ in animal models to evaluate their influence in restoration or replacement of dental abutments. The application of alloys and implant materials placed into the extracted sockets immediately after tooth extraction have reported beneficial effects; ${ }^{6,7}$ however, such techniques could not demonstrate their capability of maintaining the bony crest in its original shape for long periods of time because of their high corrosion and degradation in vivo. The biological and corrosion properties of Mg alloys have been studied in detail, ${ }^{8-11}$ and their application as orthopedic implants has been widely accepted due to (1) their characteristic biodegradability and biocompatibility in vivo, ${ }^{8-10}$ and (2) their 
established role in bone formation, eg, ability to influence mineral metabolism in the bone matrix and promotion of osteoblast specific cell signaling in vivo, without causing inflammatory reactions in the neighboring tissues. ${ }^{12}$ In addition, mechanical properties such as elastic modulus and compressive yield strength of many $\mathrm{Mg}$ based alloys closely match with that of natural bone tissue. ${ }^{13}$

In spite of the above mentioned advantages, $\mathrm{Mg}$ based alloys present some significant challenges in their usage as bio-implants, for example, (1) many Mg containing implants corrode quickly at the physiological $\mathrm{pH}$ range of 7.4-7.6, ${ }^{1,14}$ and (2) they release hydrogen $\left(\mathrm{H}_{2}\right)$ gas around the implant area leading to loss of mechanical integrity even before the tissue is healed and the new bone is mineralized. ${ }^{15,16}$ The performance of $\mathrm{Mg}$ based alloys is also affected because of the instability of the protective hydroxide film on their surface that dissolves in aqueous environments. ${ }^{17}$ These defects of $\mathrm{Mg}$ based alloys can be significantly reduced by using appropriate combinations of alloying elements with the base alloy. An ideal alloying element composition would stabilize the hydroxide film on the surface, increase their corrosion resistance and mechanical properties, and thus improve their biocompatibility and bio-efficacy. In this direction, alloys of $\mathrm{Mg}$ with strontium (Sr), rare earth elements, calcium ( $\mathrm{Ca}$ ), aluminum, trace levels of manganese, zinc, zirconium $(\mathrm{Zr})$, silicon, etc have been used to make new generations of orthopedic implants. ${ }^{18-26}$ An important factor while designing these bioactive implant surfaces is the biological response of cells to the alloys, which ultimately correlates with the success of implants in the host tissue. The idealized biological efficacy of an implant would be where the implant material gets totally amalgamated with the newly formed osseous tissue and thereafter it disintegrates into the blood stream without causing damage to the vital organs or losing its functionality. ${ }^{27}$

The main aim of the present study was to check the stability and in vivo cellular response to $\mathrm{Mg}$ alloyed with $\mathrm{Zr}, \mathrm{Sr}$ and $\mathrm{Ca}$ and to evaluate the influence of these divalent cations on the in vivo compatibility of these alloys. We hypothesize that inclusion of $\mathrm{Sr}$ in $\mathrm{Mg}$ alloys can change their surface properties and can control the potential of these alloys to interact with the osteoblast cells. This can lead to osteogenesis, osteoinduction, and osseointegration leading to extracellular matrix formation around them upon implantation. The addition of $\mathrm{Zr}$, $\mathrm{Sr}$, and $\mathrm{Ca}$ to $\mathrm{Mg}$ can influence their degradability and biocompatibility in different ways. Taking these facts into consideration, we report the effect of $\mathrm{Mg}$ alloys on the in vivo degradation, bone forming ability, and mineralization in addition to the impact of these alloys on the bone mineral content (BMC) and bone mineral density (BMD) of the implanted animals.

\section{Materials and methods Implant composition}

Cylindrical pins ( $2 \mathrm{~mm}$ diameter $\times 4 \mathrm{~mm}$ length) and discs (10 $\mathrm{mm}$ diameter/2 mm thickness) made of $\mathrm{Mg}-\mathrm{Zr}$ alloys were used as substrates for in vivo implants and for in vitro experiments respectively. The following compositions of alloys Mg-5Zr, Mg-5Zr-Ca, Mg-2Zr-5Sr and Mg-Zr-2Sr were used. All implants were prepared, and their nominal alloy compositions were determined according to the procedures described earlier. ${ }^{28}$

\section{Physicochemical characterization: X-ray diffraction and compressive strength}

The chemical compositions of the alloys were determined by wavelength dispersive X-ray fluorescence spectroscopy (S4 Pioneer; Bruker, Karlsruhe, Germany). X-ray diffraction (XRD) analysis was carried out to characterize the physicochemical properties of the Mg alloys. To characterize the phase constituents of the alloys, XRD analysis was performed at $40 \mathrm{kV}$ and $30 \mathrm{~mA}$ with a scan rate of 0.05 degree. The scan ranged between the angles of 20 degrees and 80 degrees. Compressive strengths were determined at an initial strain rate of $10^{-3} \mathrm{~s}^{-1}$ using an Instron 5567 universal tester equipped with a video extensometer (Instron, Norwood, MA, USA).

\section{Surface energy measurements}

The surface free energy of the alloys was estimated by measuring the static contact angles $(\theta)$ of two different solvents, ie, water and glycerol on the respective alloy surfaces in two independent experiments by using a sessile drop method and a video camera based contact angle goniometer OCA 40 micro (DataPhysics, Filderstadt, Germany). Average values of $\theta$ for left and right side of the drop were measured for each solvent at four different positions on each alloy surface as per the details described earlier. ${ }^{29}$ Surface energies of the substrates were calculated using SCA20_U software (DataPhysics), applying the $\mathrm{Wu}$ and Owens-Wendt method. ${ }^{30}$ Results from two independent experiments were used for calculating the mean surface energy of each alloy.

\section{Scanning electron microscopy (SEM) and hydrogen evolution measurements}

The degradation of $\mathrm{Mg}$ alloys is correlated with the amount of $\mathrm{H}_{2}$ gas evolved and was evaluated using simulated body 
fluid (SBF) as the corrosive media. The $\mathrm{H}_{2}$ evolution rate was studied at varied immersion time points and plotted as $\mathrm{H}_{2}$ evolution versus immersion time. The $\mathrm{Mg}$ alloy substrates were gold-coated in an ion sputter coater SC7620 (Quorum Technologies, Ringmer, UK) and the surface morphology were visualized by SEM with an accelerated voltage of $5 \mathrm{kV}$ (3400 N Hitachi; Hitachi Ltd, Tokyo, Japan).

\section{Implant preparation and surgery}

Prior to surgery, all implants were sonicated in $2 \%$ chromium oxide for 20-30 minutes, followed by a 10 minute wash with each acetone, ethanol, and distilled water, then they were air-dried and sterilized. Male New Zealand White rabbits of approximate age 4-6 months and weighing $2.5 \pm 0.85 \mathrm{~kg}$ were used for in vivo study. Three animals were used for each alloy and as controls in each experiment. A total of 30 animals were used for the in vivo experiments, and we report the results of two experiments for an implant period of 3 months. Alloys were implanted in a hole drilled in the lower end of the femur bone of rabbits as per the surgical procedures approved by the institutional animal ethics committee of CSIR-Centre for Cellular and Molecular Biology and Deakin University. Control animals did not receive an implant but did have a hole drilled the same size as the implant. Animal surgery was performed in an operation room. The animals were administered local anesthetics (ketamine hydrochloride [25-40 $\mathrm{mg} / \mathrm{kg}$ body weight] and xylazine hydrochloride [10 mg/kg body weight]) (Troy laboratories, Glendenning, Australia) intramuscularly prior to surgery. The surgery area on the left knee was shaved, and the surface was disinfected with antimicrobial povidone iodine solution (Win-Medicare, New Delhi, India). After exposing the outer lateral side of the tibial end of the left femur, a small cavity of approximately $5 \mathrm{~mm}$ depth was drilled through the cortical region about $1 \mathrm{~cm}$ above the knee joint using a hand-operated surgical drill attached to a drill bit of $2.4 \mathrm{~mm}$ diameter and $10 \mathrm{~mm}$ length. A single implant piece was pressed into the drilled cavity in each animal. After this procedure, the muscular area around the implant was sutured using absorbable suture material (Ethicon, Somerville, NJ, USA), and the skin layer surrounding the muscular region was sutured by interrupted suturing with non-absorbable silk thread. All the animals were kept under close observation for 3 months, during which time no mortality or morbidity in the animals was observed. Meloxicam analgesic (Intas Pharma, Ahmedabad, India) was administered orally at $3 \mathrm{mg} / \mathrm{kg}$ body weight twice a day for a period of three days; local application of Lorexane ointment (Virbac Animal Health, Mumbai, India) was done until the wound healed. After 3 months the animals were euthanized using carbon dioxide inhalation for biochemical, radiological, and histological analyses as described below.

\section{Blood-cell count and serum biochemical measurements}

Blood samples were collected from all animals, by retroorbital puncture, 3 months post-implantation. For blood cell count, samples were collected in K3-EDTA tubes and routine analysis of blood samples were performed in a Tulip CounCell23 automatic blood analyzer (The Tulip Group, Goa, India). Serum samples were obtained by centrifuging the collected blood at 3,000 rpm for 10 minutes at $4^{\circ} \mathrm{C}$ and stored in $-80^{\circ} \mathrm{C}$ until use. Serum biochemical tests were done in Tulip CORALAB-3000 serum analyzer (Coral Clinical Systems, The Tulip Group).

\section{In vivo radiography}

To follow up the healing process after the surgery and before removal of the implanted femur, radiography was performed to measure the BMC and BMD around the implant area of live animals at 1, 2, and 3 months after implantation using dual energy X-ray absorptiometry (DXA) in a Hologic Discovery QDR Series (Bedford, MA, USA). The mineral concentration and density of the region was calculated using the QDR software.

\section{Histochemical staining}

Immediately after euthanizing the animals, bone specimens (size of $\sim 1 \mathrm{~cm}^{3}$ ) from the peri-implant area from all animals were excised and fixed in 10\% buffered formaldehyde at $4^{\circ} \mathrm{C}$ for a period of 3 days. After fixation the specimens were dehydrated in increasing grades of isopropyl alcohol (70\%, $80 \%, 95 \%, 100 \%$ ) and cleared with xylene. The samples were embedded in methyl-methacrylate and, to facilitate complete infiltration of the bone tissue with the embedding medium, cold polymerization of methyl-methacrylate was done with specimens at $4^{\circ} \mathrm{C}$ for 3 days. Benzoyl peroxide was used as initiator, and final polymerization was done with N-N Dimethyl-p-toluidine as accelerator. Sections of $10 \mu \mathrm{m}$ thickness of each specimen were cut using a saw microtome Leica SP1600 (Leica Microsystems, Wetzlar, Germany) in the perpendicular plane to the implant surface (sagittal sections). Each bone was cut into eight to 12 sagittal sections through the marrow region, depending on their thickness and three sections from each bone were used for single staining. Images of the best stained sections were reported in this study. Sections were stained with hematoxylin 
and eosin (H\&E) and Masson's trichrome (MT) ${ }^{31}$ to study the cellularity and mineralization of osteoblasts near the bone-implant interface. Tartrate-resistant acid phosphatase (TRAP) assay was carried out to study bone remodeling at the peri-implant bone interface and to assess the osteoclast activity. Slides were incubated in acetate buffer at room temperature and incubated in substrate solution prepared in acetate buffer with naphthol AS-MX phosphate (SigmaAldrich, St Louis, MO, USA) and Fast-Red (Sigma-Aldrich) as enzyme substrates, and Orange G (Sigma Aldrich) as azo dye at $37^{\circ} \mathrm{C}$ for $1-4$ hours until the osteoclasts were bright red in color, after which the sections are washed in distilled water and mounted in Permount Mounting Medium (Thermo Fisher Scientific, Waltham, MA, USA).

\section{Immunohistochemistry}

Collagen type-I $(\mathrm{Col})$ immunostaining was carried out to study the bone forming activity. After deplasticization, sections were rehydrated and given a brief wash in Tris-buffered saline (TBS). This was followed by an antigen retrieval step. Blocking of endogenous peroxidase activity was carried out using 3\% hydrogen peroxide for 30 minutes. The sections were incubated in 3\% bovine serum albumin for nonspecific binding of antibody. Further, sections were incubated with primary antibody (mouse monoclonal IgG1 anti-bovine Col antibody) (Sigma-Aldrich) at room temperature for 1 hour and washed in TBS three times. Thereafter, sections were incubated with horseradish peroxidase-tagged secondary antibody (rabbit anti-mouse IgG) (Sigma-Aldrich) for 1 hour at room temperature and washed three times with TBS. Diaminobenzidine (Sigma-Aldrich) was used as a substrate for the colored visualization of peroxidase activity. After color development, sections were washed in distilled water and mounted using Kaiser's glycerol gelatin (Merck KGaA, Darmstadt, Germany). Images of the stained sections were taken using Zeiss Axioplan $200 \mathrm{M}$ microscope (Carl Zeiss, Oberkochen, Germany) fitted with an Axiocam Mrc digital camera and the images were processed via the Axiovision Version 5 software provided by the instrument supplier.

\section{Statistical analysis}

The statistical evaluation of data obtained from three different animals for each alloy and controls was used for serum biochemical measurements, estimation of blood counts, and determination of BMC and BMD of the bones in the implanted area. One-way analysis of variance (ANOVA) with unstacked technique and Tukey's family error rate of 5 was performed using MiniTab software (MiniTab Inc, State
College, PA, USA). Standard errors in the data points were determined at $95 \%$ confidence level. $P$-values of less than 0.05 were considered statistically significant. Data presented in the graphs or tables are mean values \pm standard error of the mean.

\section{Results}

The detailed alloy compositions of all the four substrates are given in Table 1. As can be seen, the substrates were almost free of contaminants such as aluminum, iron, manganese, and silicon, and the relative contents of base $(\mathrm{Mg})$ and alloying $(\mathrm{Zr}, \mathrm{Sr}$, and $\mathrm{Ca})$ metals were as per the desired values in every substrate. The XRD data (Figure 1) showed that all alloys contained a dominant and primary $\alpha-\mathrm{Mg}$ phase. In addition to this, in $\mathrm{Mg}-2 \mathrm{Zr}-5 \mathrm{Sr}$ and $\mathrm{Mg}-\mathrm{Zr}-2 \mathrm{Sr}$ alloys, a strong and intermediate peak for the $\mathrm{Mg}_{17} \mathrm{Sr}_{2}$ intermetallic phase could be seen; this peak was absent in the other two alloys. Intermetallic Mg-Zr peaks were absent in alloys; this could be attributed to their low solubility in the presence of $\mathrm{Mg}$ and distribution of $\alpha-\mathrm{Zr}$ particles in $\mathrm{Mg}$ matrix, as has been explained by others. ${ }^{32}$ Almost all the alloys exhibited good mechanical strength, that matched the properties of normal bone tissue, making these alloys suitable and potential candidates for temporary implant applications. The compressive strengths of Mg-5Zr, Mg-5Zr-Ca, Mg-2Zr-5Sr, and $\mathrm{Mg}-\mathrm{Zr}-2 \mathrm{Sr}$ alloys were estimated to be $237.8 \mathrm{MPa}$, 255.7 MPa, 209.7 MPa, and 242.9 MPa, respectively, which was within the range of the compressive strength of normal cortical bone (164-240 MPa), ${ }^{14}$ except Mg-5Zr-Ca. As can be seen, addition of Ca to the $\mathrm{Mg}-\mathrm{Zr}$ base alloy in $\mathrm{Mg}-5 \mathrm{Zr}-\mathrm{Ca}$ made it stiffer and more inflexible than the other three alloys. The SEM images of the alloys before incubation (Figure S1) in the culture media showed rough surfaces, with scattered distribution of particles having a floral arrangement. After incubation in culture media (Figure 2), we observed the appearance of cracks, pits, and more roughened edges on all surfaces that could be biologically advantageous for the implants because such surface topographies can accelerate the osteoblast adhesion. ${ }^{33}$ Table 2 and Figures S2 and S3,

Table I Nominal compositions magnesium-based alloys

\begin{tabular}{lllllllll}
\hline Alloy & \multicolumn{7}{l}{ Chemical composition (\% wt) } \\
\cline { 2 - 9 } & $\mathbf{Z r}$ & Sr & Ca & Al & Si & Fe & Mn & Mg \\
\hline Mg-5Zr & 4.88 & - & - & 0.02 & 0.01 & 0.01 & 0.01 & Balance \\
Mg-5Zr-Ca & 4.41 & - & 0.91 & - & - & 0.01 & 0.01 & Balance \\
Mg-2Zr-5Sr & 1.89 & 4.8 & - & 0.03 & 0.02 & 0.01 & 0.01 & Balance \\
Mg-Zr-2Sr & 0.92 & 1.82 & - & 0.04 & 0.02 & 0.02 & 0.01 & Balance \\
\hline Abron
\end{tabular}

Abbreviations: $\mathrm{Zr}$, zirconium; $\mathrm{Sr}$, strontium; $\mathrm{Ca}$, calcium; $\mathrm{Al}$, aluminum; $\mathrm{Si}$, silicon; $\mathrm{Fe}$, iron; Mn, manganese; Mg, magnesium; wt, weight. 

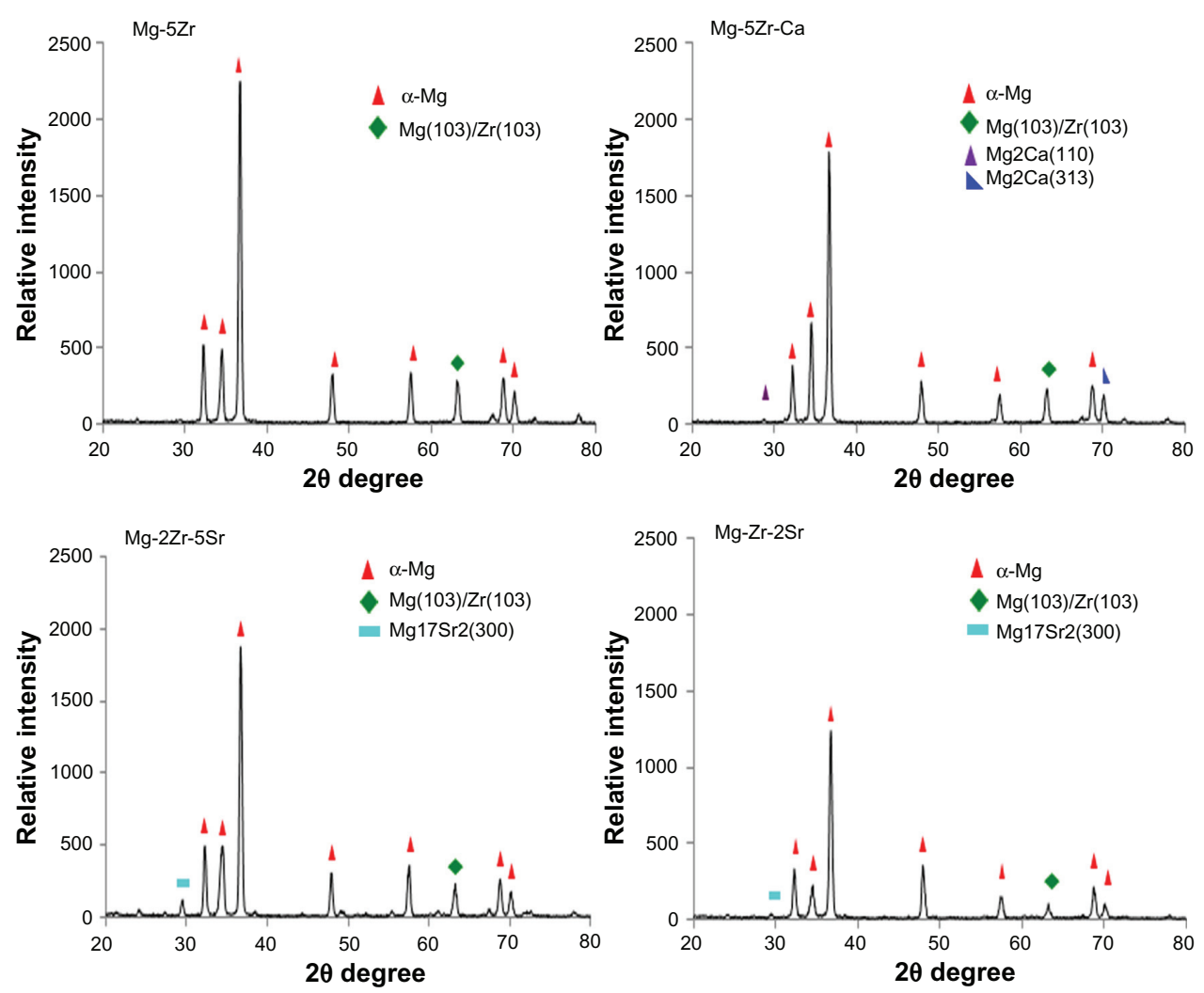

Figure I X-ray diffraction spectra of four magnesium alloys.

Abbreviations: $\mathrm{Ca}$, calcium; $\mathrm{Mg}$, magnesium; $\mathrm{Zr}$, zirconium; $\mathrm{Sr}$, strontium.
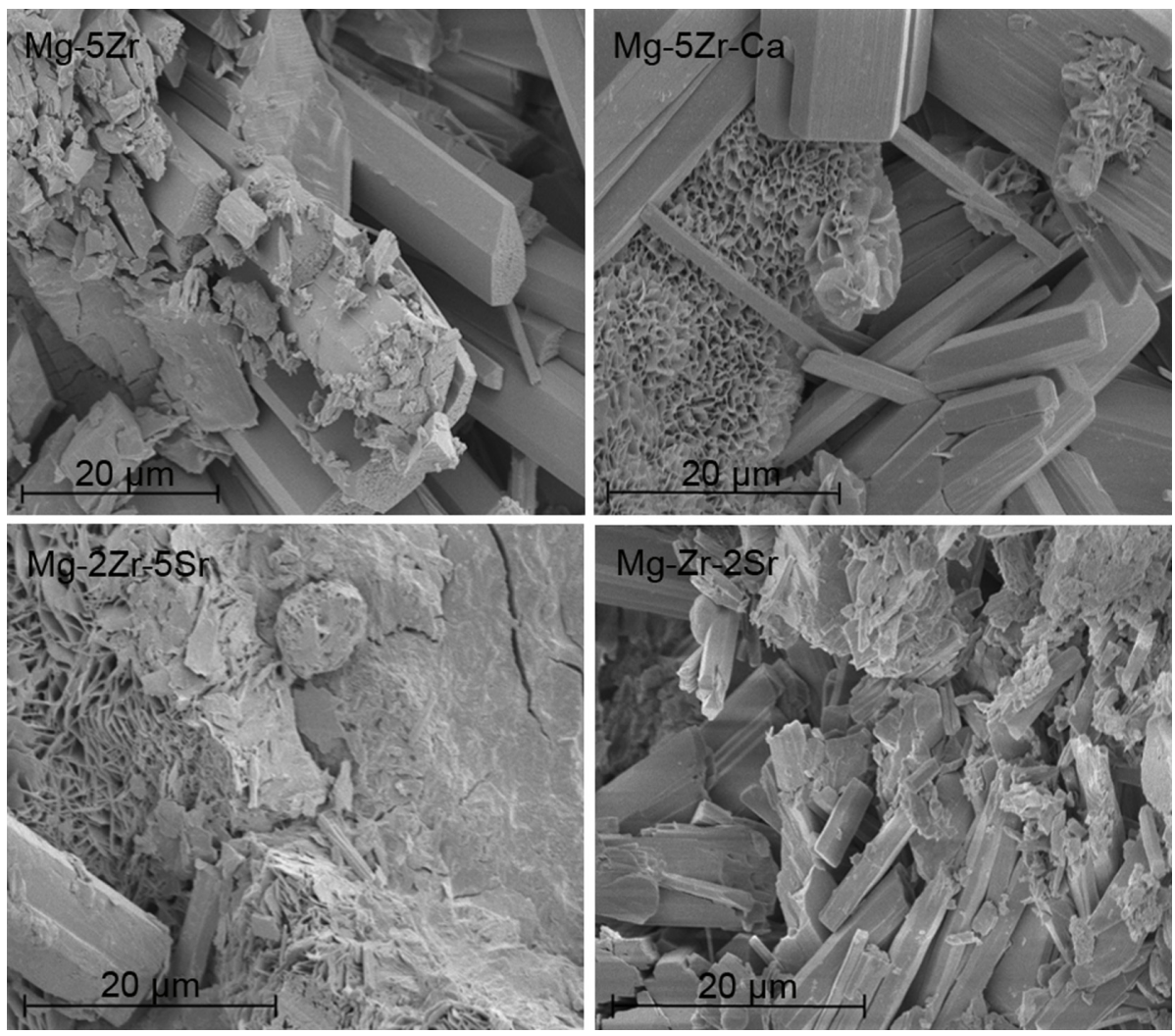

Figure 2 Scanning electron micrographs of magnesium alloys after incubation in the culture media for 7 days. Abbreviations: $\mathrm{Ca}$, calcium; $\mathrm{Mg}$, magnesium; $\mathrm{Zr}$, zirconium; $\mathrm{Sr}$, strontium. 
Table 2 Mean left and right contact angle (CA) values and the respective surface energies (SE), with statistical standard deviations in the values, of all the four magnesium-based alloys

\begin{tabular}{llll}
\hline Alloy & Liquid & Left & Right \\
\hline Mg-5Zr & Water CA & $25.25^{\circ} \pm 0.92^{\circ}$ & $27.25^{\circ} \pm 0.49^{\circ}$ \\
& Glycerol CA & $43.9^{\circ} \pm 1.27^{\circ}$ & $46.65^{\circ} \pm 0.07^{\circ}$ \\
& Surface energy & $66.76 \mu \mathrm{J} / \mathrm{mm}^{2}$ & $66.53 \mu \mathrm{J} / \mathrm{mm}^{2}$ \\
& Average SE & $66.64 \pm 0.162 \mu \mathrm{J} / \mathrm{mm}^{2}$ \\
$M g-5 Z r-C a$ & Water CA & $23.3^{\circ} \pm 0.71^{\circ}$ & $24.3^{\circ} \pm 0.99^{\circ}$ \\
& Glycerol CA & $45.7^{\circ} \pm 0.57^{\circ}$ & $48.1^{\circ} \pm 1.98^{\circ}$ \\
& Surface energy & $68.27 \mu \mathrm{J} / \mathrm{mm}^{2}$ & $69.40 \mu \mathrm{J} / \mathrm{mm}^{2}$ \\
& Average SE & $68.83 \pm 0.79 \mu \mathrm{J} / \mathrm{mm}^{2}$ \\
$M g-2 Z r-5 S r$ & Water CA & $43.45^{\circ} \pm 0.64^{\circ}$ & $41.65^{\circ} \pm 2.33^{\circ}$ \\
& Glycerol CA & $53.65^{\circ} \pm 6.15^{\circ}$ & $54.35^{\circ} \pm 3.04^{\circ}$ \\
& Surface energy & $55.60 \mu \mathrm{J} / \mathrm{mm}^{2}$ & $57.17 \mu \mathrm{J} / \mathrm{mm}^{2}$ \\
& Average SE & $56.38 \pm 1.11 \mu \mathrm{J} / \mathrm{mm}^{2}$ \\
Mg-Zr-2Sr & Water CA & $63.85^{\circ} \pm 1.76^{\circ}$ & $64.15^{\circ} \pm 1.91^{\circ}$ \\
& Glycerol CA & $74.4^{\circ} \pm 2.68^{\circ}$ & $73.55^{\circ} \pm 0.64^{\circ}$ \\
& Surface energy & $42.42 \mu \mathrm{J} / \mathrm{mm}^{2}$ & $41.85 \mu \mathrm{J} / \mathrm{mm}^{2}$ \\
& Average SE & $42.13 \pm 0.40 \mu \mathrm{J} / \mathrm{mm}^{2}$ \\
\hline
\end{tabular}

Abbreviations: $\mathrm{Zr}$, zirconium; $\mathrm{Sr}$, strontium; $\mathrm{Ca}$, calcium; $\mathrm{Mg}$, magnesium.

respectively, show the calculated free surface energy values, the shapes of individual drops, and the left and right contact angles of all the alloys. Mean contact angles of the alloys were between $23^{\circ}-75^{\circ}$, and the corresponding surface energies were in the range of $40-70 \mu \mathrm{J} / \mathrm{mm}^{2}$, as shown in Table 2 . Based on this data, we concluded that the surface energies of the alloys were in the following order: $\mathrm{Mg}-5 \mathrm{Zr}-\mathrm{Ca}>\mathrm{Mg}-$ $5 \mathrm{Zr}>\mathrm{Mg}-2 \mathrm{Zr}-5 \mathrm{Sr}>\mathrm{Mg}-\mathrm{Zr}-2 \mathrm{Sr}$. It is known that substrates with low surface energies are more hydrophobic than surfaces with high surface energies. ${ }^{34}$ Therefore, in our study, since $\mathrm{Mg}-\mathrm{Zr}-2 \mathrm{Sr}$ showed the least surface energy and $\mathrm{Mg}-5 \mathrm{Zr}-\mathrm{Ca}$ the most, $\mathrm{Mg}-\mathrm{Zr}$-2Sr was considered as most hydrophobic and $\mathrm{Mg}-5 \mathrm{Zr}-\mathrm{Ca}$ as most hydrophilic. Based upon the compressive strengths and the composition of the alloys, we decided to compare the bone inducing activity of $\mathrm{Mg}-5 \mathrm{Zr}-\mathrm{Ca}$ versus $\mathrm{Mg}-5 \mathrm{Zr}$ implants and $\mathrm{Mg}-2 \mathrm{Zr}-5 \mathrm{Sr}$ versus $\mathrm{Mg}-\mathrm{Zr}-2 \mathrm{Sr}$ implants. The first grouping was to evaluate the role of $\mathrm{Ca}$ and the second for evaluating the combined roles of $\mathrm{Zr}$ and $\mathrm{Sr}$ in the alloys.

The histological study of the implant-induced bone properties at 12 weeks after implantation of the alloys gave us a two-fold approach: on one hand, the focus was on identifying the cell types within the newly induced bone tissue by doing H\&E and TRAP staining, and on the other hand, features of the extracellular matrix $(\mathrm{ECM})$ of new bone were depicted by Col immunostaining and MT staining. H\&E staining showed no significant features of local inflammatory responses around the implants, but the fibrous encapsulation of the $\mathrm{Mg}-5 \mathrm{Zr}$ and $\mathrm{Mg}-5 \mathrm{Zr}-\mathrm{Ca}$ implant-induced new bone (NB) indicated inflammatory response toward these implants (Figure 3). H\&E staining of the $\mathrm{Mg}-5 \mathrm{Zr}-$ and $\mathrm{Mg}-5 \mathrm{Zr}-\mathrm{Ca}$-induced bones also showed a non-uniform bone formation pattern that was rich in fibroblast-like cells and an ECM that was filled with remnants of degraded alloy particles. These features of $\mathrm{Mg}-5 \mathrm{Zr}$ and Mg-5Zr-Ca implant-induced bones were indicative of "distance osteogenesis" behavior. In contrast, $\mathrm{Mg}-2 \mathrm{Zr}-5 \mathrm{Sr}-$ and $\mathrm{Mg}-\mathrm{Zr}$-2Sr implant-induced bones showed firm adhesion of the new tissue to the implant surface and a uniform osteoblastrich bone tissue, which represented the features of "contact osteogenesis" (see Discussion section). TRAP staining of the peri-implant site showed a significantly higher number of osteoclasts in the $\mathrm{Mg}-2 \mathrm{Zr}-5 \mathrm{Sr}-$ and $\mathrm{Mg}-\mathrm{Zr}$-2Sr-induced bones as compared to $\mathrm{Mg}-5 \mathrm{Zr}$ and $\mathrm{Mg}-5 \mathrm{Zr}-\mathrm{Ca}$ (Figure 4), indicating more appropriate bone remodeling behavior in the former. We also noticed the complete degradation of the $\mathrm{Mg}-2 \mathrm{Zr}-5 \mathrm{Sr}$ and $\mathrm{Mg}-\mathrm{Zr}-2 \mathrm{Sr}$ implant materials, which could be responsible for the activation of osteoclasts. Between the Mg-2Zr-5Sr and $\mathrm{Mg}-\mathrm{Zr}-2 \mathrm{Sr}$ implants, the total number of TRAP-positive cells was more in the Mg-2Zr-5Sr-induced bones (Figure 4) than in $\mathrm{Mg}-\mathrm{Zr}-2 \mathrm{Sr}$-induced bones. The poor degradation of the $\mathrm{Mg}-5 \mathrm{Zr}$ and $\mathrm{Mg}-5 \mathrm{Zr}-\mathrm{Ca}$ implants, even after 12 weeks, indicated their lesser osteoclast-inducing capacity.

Positive Col immunostaining could be seen in the ECMs of all the new induced peri-implant bones, but its levels were higher in $\mathrm{Mg}-2 \mathrm{Zr}-5 \mathrm{Sr}$ - and $\mathrm{Mg}-\mathrm{Zr}-2 \mathrm{Sr}$-induced bones (Figure 5). Collagen type-I is one of the most abundant protein of the mineralized bone matrix, and it is a marker of early osteoblast differentiation. ${ }^{35}$ It is synthesized in the osteoblasts, and its secretion in the matrix indicates formation of an osteoid matrix. MT staining was used to differentiate the unmineralized osteoids (red staining) from the mineralized ECM (blue staining) of mature bone tissue in the implant area. The bone response around the implants $\mathrm{Mg}-5 \mathrm{Zr}$ and Mg-5Zr-Ca (Figure 6) were separated by a gap interface rich in fibrous tissue. The thickness of the fibrous tissue enclosing the implant $\mathrm{Mg}-5 \mathrm{Zr}$ was $135 \mu \mathrm{m}$ and that of $\mathrm{Mg}-5 \mathrm{Zr}-\mathrm{Ca}$ was $176 \mu \mathrm{m}$. The cellular details of the dense fibrous envelope formed is well depicted in the MT stained sections, where the well-structured collagen fibers are stained blue-green in color and the cell nuclei in red. The peri-implant site of these implants showed superior bone contact after 3 months of healing, as depicted in Figure 6. These images are depictive of mature woven bone, which distinguishes between osteoblasts and fibroblast mineralization. Implant $\mathrm{Mg}-\mathrm{Zr}-2 \mathrm{Sr}$ represented prominent osteogenic activity with mature woven trabecular bone formation after 3 months, with the implant site filled with spongy bone and no degradable particles, illustrating 

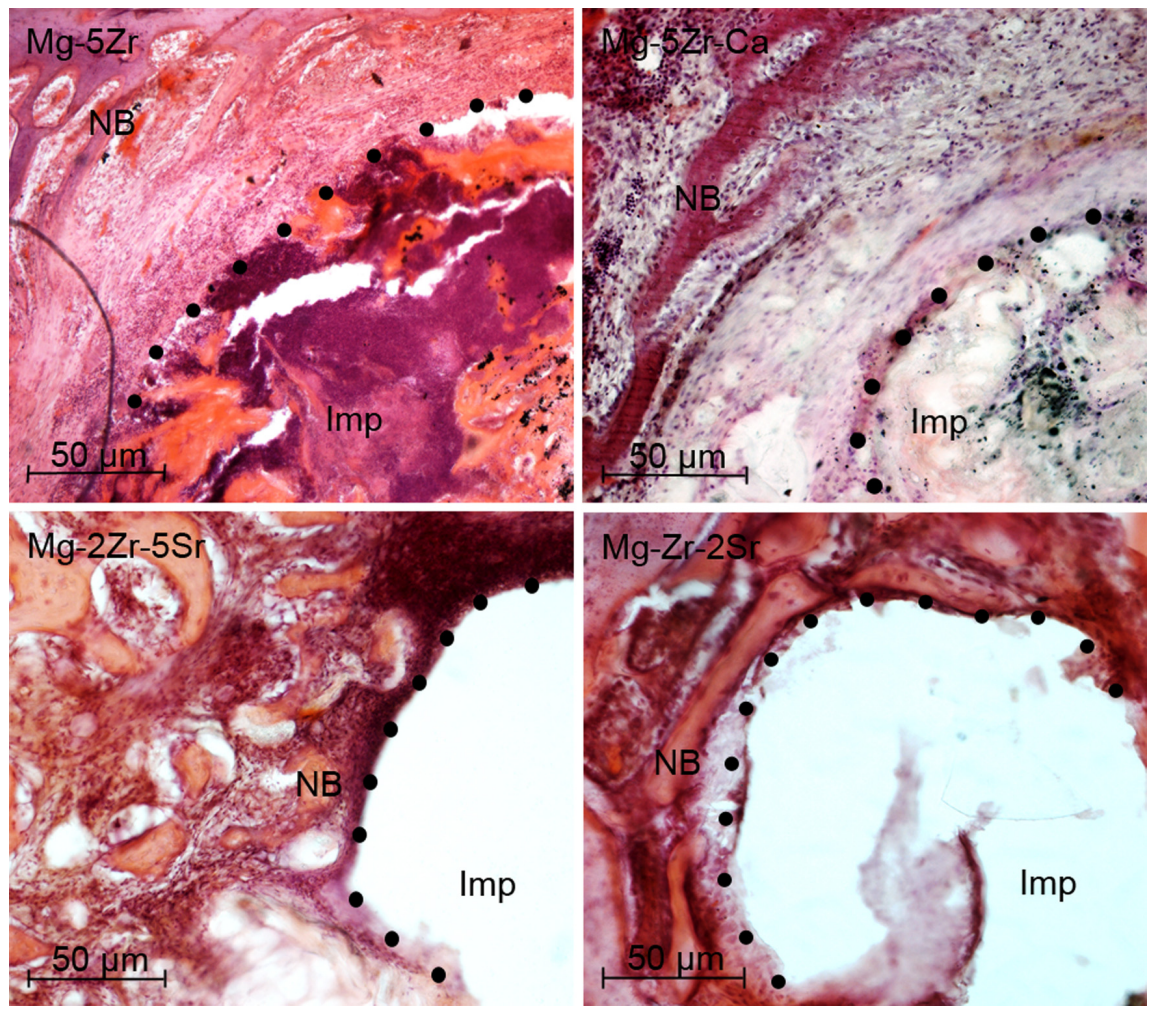

Figure 3 Hematoxylin and eosin stained bone sections (100x) of all magnesium alloys 3 months post-implantation.

Note: The dots represent the implant-bone interface.

Abbreviations: Imp, implant site; NB, newly formed trabecular bone; $\mathrm{Ca}$, calcium; $\mathrm{Mg}$, magnesium; $\mathrm{Zr}$, zirconium; $\mathrm{Sr}$, strontium.
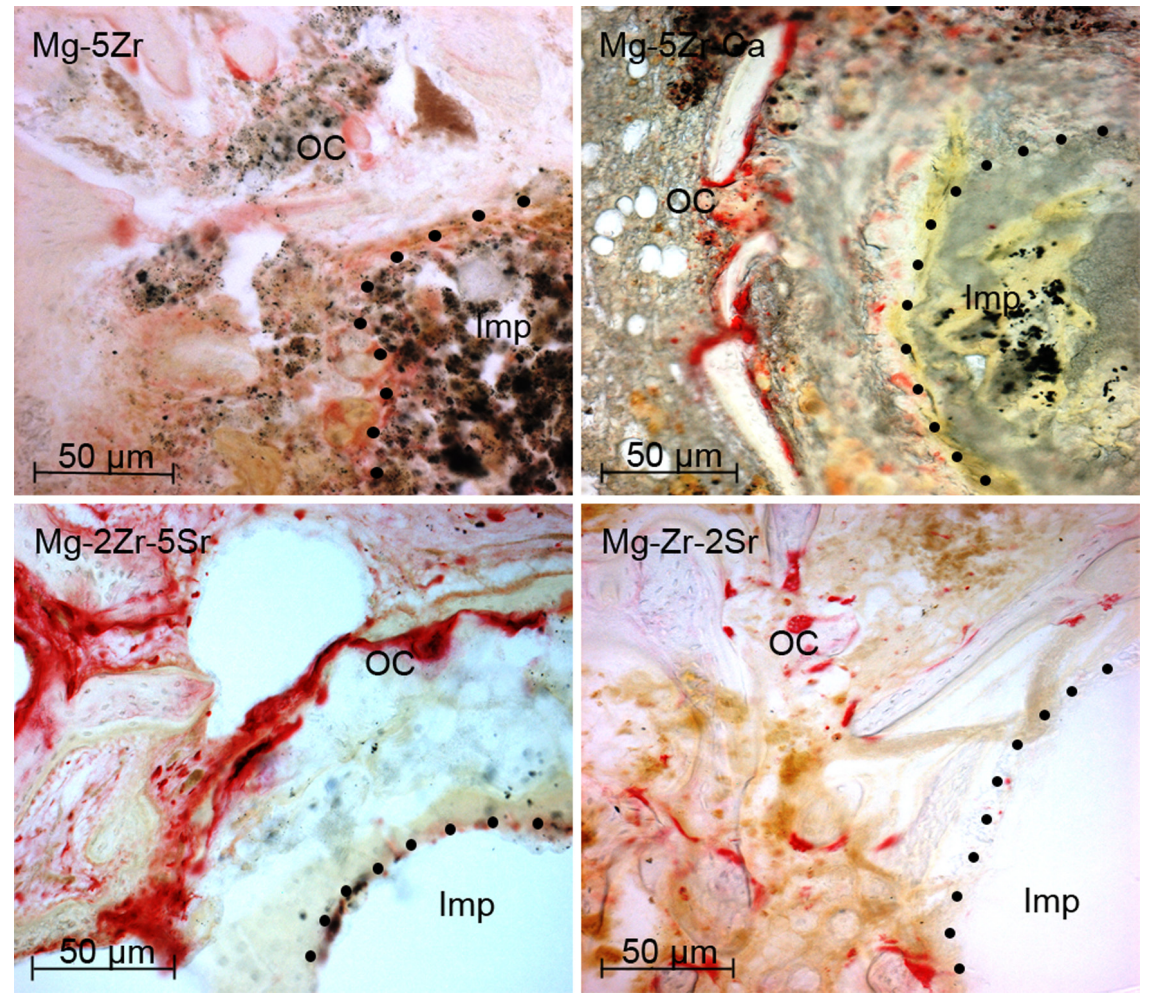

Figure 4 Tartrate-resistant acid phosphatase staining of bone sections (100x) 3 months post-implantation.

Notes: The red colored cells represent osteoclasts at the peri-implant interface. The dots represent the implant-bone interface.

Abbreviations: Imp, implant site; OC, osteoclasts; Ca, calcium; Mg, magnesium; Zr, zirconium; Sr, strontium. 

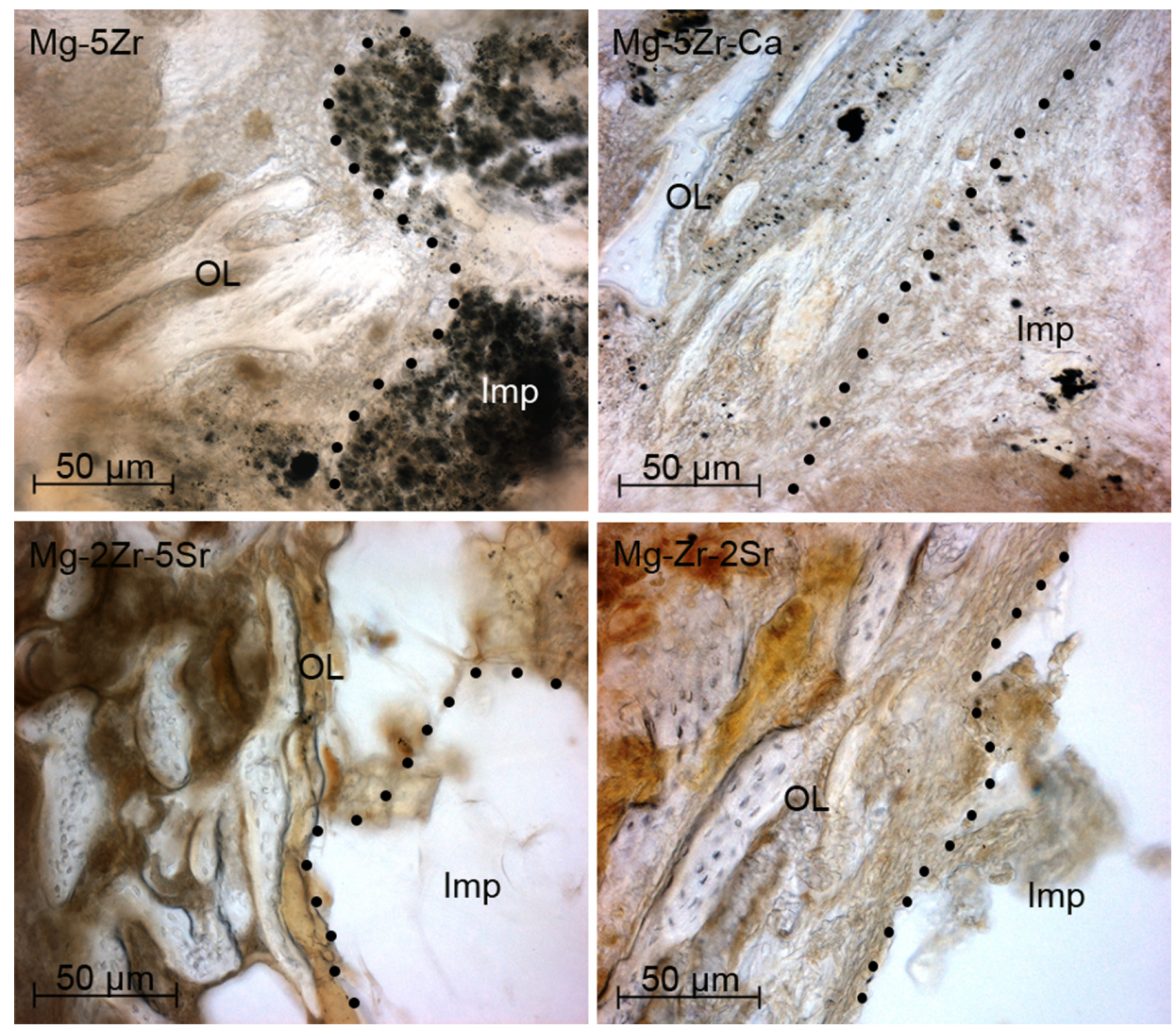

Figure 5 Immunostaining of implanted bone sections (100X) by collagen type-l, 3 months post-implantation.

Notes: Panels show osteoblasts lining the newly formed bone. The osteoblasts occupied significantly higher bone surface near the implant site in $\mathrm{Mg}-2 \mathrm{Zr}-5 \mathrm{Sr}$ and $\mathrm{Mg}$ - Zr-2Sr. The dots represent the implant-bone interface.

Abbreviations: Imp, implant site; OL, osteoblast lining; Ca, calcium; Mg, magnesium; Zr, zirconium; Sr, strontium.

uniform disintegration of the implant. The newly formed bone was completely mineralized in $\mathrm{Mg}-\mathrm{Zr}-2 \mathrm{Sr}$, while Mg-2Zr-5Sr showed unmineralized bone (osteoid) in red when stained with MT. The osteoblasts lining the trabecular surface were predominant around the peri-implant interface of the implants $\mathrm{Mg}-2 \mathrm{Zr}-5 \mathrm{Sr}$ and $\mathrm{Mg}-\mathrm{Zr}-2 \mathrm{Sr}$, as shown by MT stained images. The mean BMC and BMD values of the implant-induced bones (three animals for each alloy) and three control animals recorded at monthly intervals for three months are shown in Figure 7A and B, respectively. BMC values for control animals did not show any increase with time, whereas in all implant containing bones, the values increased significantly by the third month, when for Mg-2Zr-5Sr and $\mathrm{Mg}-\mathrm{Zr}-2 \mathrm{Sr}$ implants, they were higher than $\mathrm{Mg}-5 \mathrm{Zr}$ and Mg-5Zr-Ca. Interestingly, BMD values for all the implants remained more or less similar to control values, showing no significant change. This difference in the variation of BMC and BMD values implies that after 3 months, the total area (or volume) of healed bone in $\mathrm{Mg}-2 \mathrm{Zr}-5 \mathrm{Sr}$ and $\mathrm{Mg}-\mathrm{Zr}-2 \mathrm{Sr}$ implant-bearing wounds was bigger than the healed areas of control or Mg-5Zr-Ca implant-bearing bones. Further, this data reflects the osteoinductive property of the $\mathrm{Mg}$ alloys. Hydrogen evolution rates were calculated based on immersion tests performed by incubating the substrates in SBF, and Figure $7 \mathrm{C}$ shows the data for all the four alloys. As expected, all the substrates exhibited release of $\mathrm{H}_{2}$ gas upon immersion in SBF, which was in direct correlation with their immersion time. Mg-5Zr-Ca showed maximum $\mathrm{H}_{2}$ evolution at 72 hours, indicating that it had corroded and dissolved entirely in SBF by that time. In contrast, the Sr-containing alloys showed a more optimized $\mathrm{H}_{2}$ evolution and degradation behavior in relation to those alloys that did not contain $\mathrm{Sr}$. A representative X-ray image of implanted area for the $\mathrm{Mg}$-Zr-2Sr implant is shown in Figure 7D. None of the alloys showed any indication of peri-implant gas bubble formation or its shadows up to 3 months. It is, however, possible that small amounts of $\mathrm{H}_{2}$ gas were generated around the implant area within the first few days after implantation. This release of $\mathrm{H}_{2}$ gas was considered within tolerable limits, and therefore $\mathrm{H}_{2}$ evolution from the implants was of little concern in our study. We also noticed that 3 months post-implantation, the implanted pellets of the alloy had degraded, and their edges had become too 


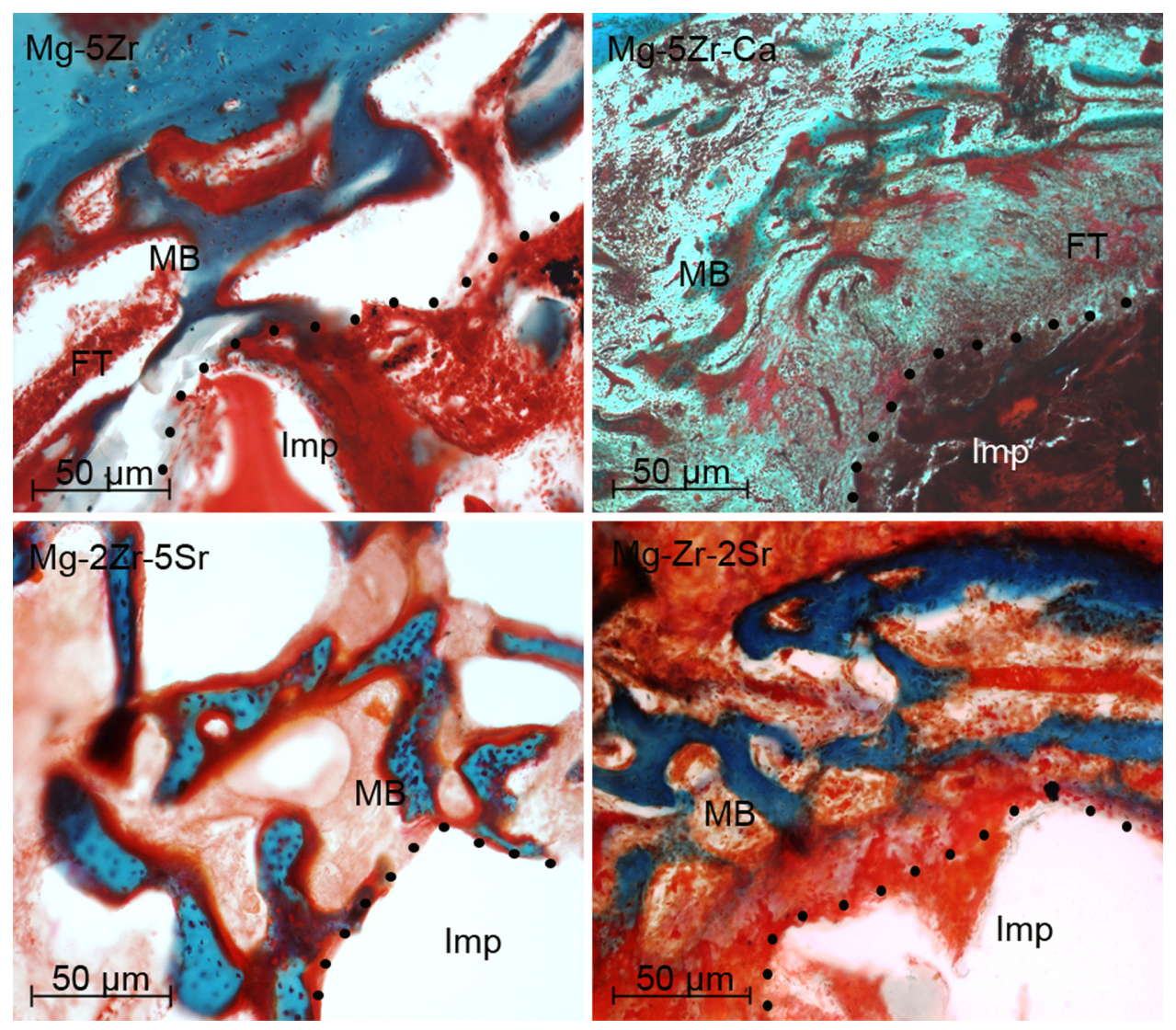

Figure 6 Masson's Trichrome stained sections (100x) of magnesium alloys 3 months post-implantation.

Note: The dots represent the implant bone interface.

Abbreviations: FT, fibrous tissue; Imp, implant site; MB, mineralized bone; Ca, calcium; Mg, magnesium; Zr, zirconium; Sr, strontium.

fuzzy to be recognized (Figure 7D). The degradation levels of the implants were variable from alloy to alloy, which became more evident in the histological analysis.

Total blood-cell count and serum biochemical analysis of the rabbits performed 3 months after implantation gave information regarding inflammation and liver and kidney functions. The blood examination results are listed in Table 3. Rabbits implanted with $\mathrm{Mg}-5 \mathrm{Zr}$ and $\mathrm{Mg}-2 \mathrm{Zr}-5 \mathrm{Sr}$ showed a slight increase in lymphocytes, hematocrit, mean corpuscular volume, and mean cell hemoglobin concentration. An increase in platelet count was found in $\mathrm{Mg}-\mathrm{Zr}-2 \mathrm{Sr}$. However, these elevations do not indicate any kind of disturbances in the blood count. All the animals were in good physical condition and free from any kind of diseases within the prescribed implant period. Furthermore, it did not indicate any kind of systemic inflammatory reactions. Serum biochemical values of urea, uric acid, creatinine, serum glutamic oxaloacetic transaminase (SGOT), serum glutamic pyruvic transaminase (SGPT), alkaline phosphatase (ALP), total protein, $\mathrm{Mg}, \mathrm{Ca}$, and chloride from rabbits implanted with $\mathrm{Mg}$ alloys are listed in Table 4. The kidney-related parameters include urea, uric acid, and creatinine levels in the serum. Liver functions were monitored by checking SGOT, SGPT, ALP, and total protein, whereas normal body electrolytes were monitored by checking the total $\mathrm{Mg}, \mathrm{Ca}$ and chloride levels in the serum. All the alloys showed elevated values for urea as compared to the control, except Mg-Zr-2Sr. This could indicate that the degradation of $\mathrm{Mg}$ alloys caused a limited effect on kidney function. Serum ALP and Ca showed elevated values beyond the normal recommended levels. All the other serum parameters were within the normal range. This suggests that by 3 months, the liver function was not affected by degradation of these alloys. Balance of electrolytes in the body is necessary for normal functions of cells and organs. The unaltered electrolyte balance signifies that the in vivo degradation of Mg alloys did not cause any disturbance to the normal electrolyte levels of the implanted subjects.

\section{Discussion}

Implant stability plays a vital role in determining the biological efficacy of endosseous prostheses. The material stability criteria becomes even more critical in the case of 
A
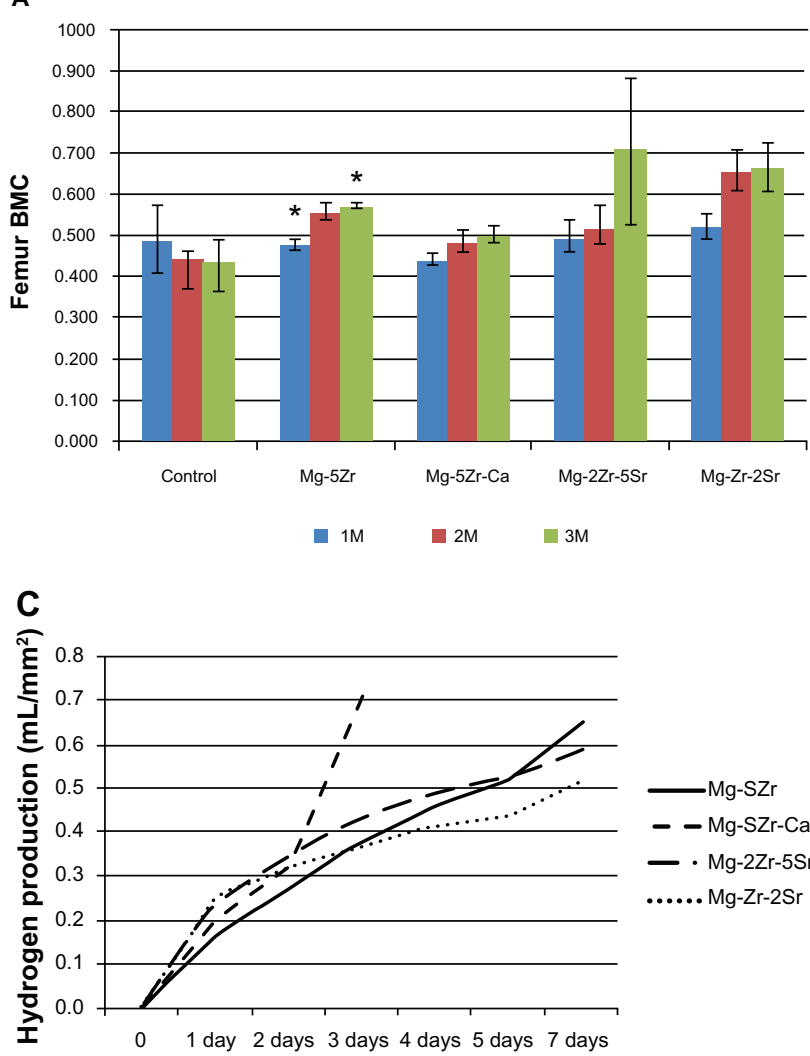

Time (days)

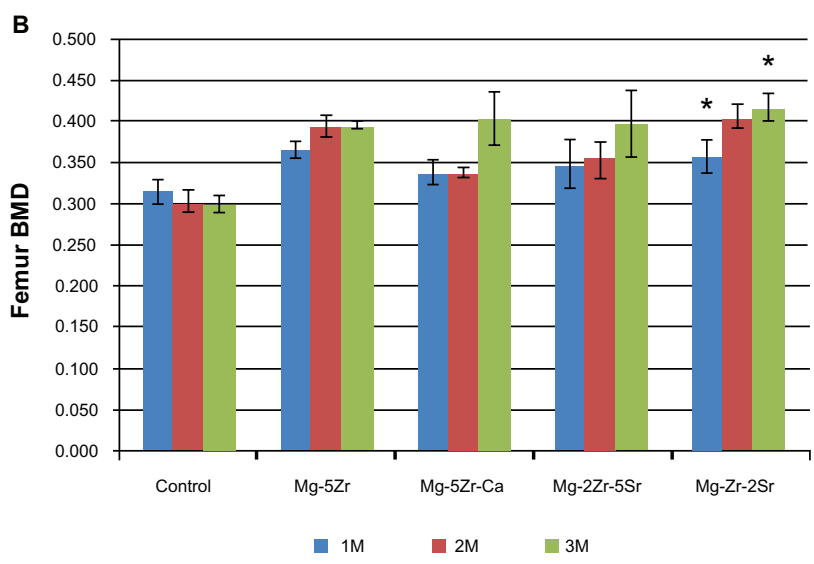

D

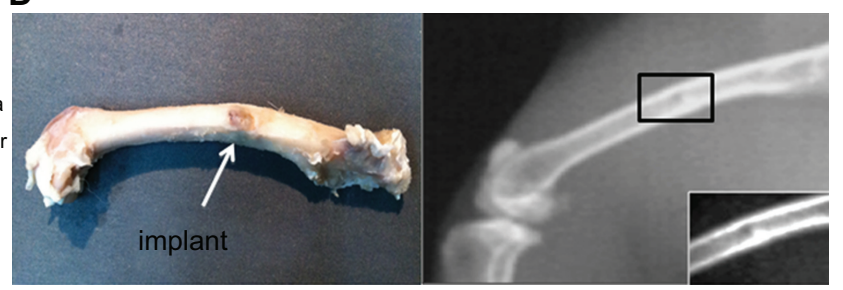

Figure 7 Physiological, physicochemical, and anatomical effects of the four magnesium alloys used for implantation.

Notes: Panels A and B show BMC and BMD, respectively, of the implanted animals after I, 2, and 3 months post-implantation for control and experimental animals. Data shown are mean values taken from three experimental animals in each time point. Panel $\mathbf{C}$ shows hydrogen evolution rates of magnesium alloys upon incubation in simulated body fluid for 7 days. Panel $\mathbf{D}$ shows X-ray radiograph of a representative implanted live animal (Mg-Zr-2Sr) after 3 months implantation.

Abbreviations: $\mathrm{Ca}$, calcium; Mg, magnesium; Zr, zirconium; Sr, strontium; BMC, bone mineral content; BMD, bone mineral density; IM, one month; 2M, two months; 3M, three months.

biodegradable implants because it is essential for the implant to induce sufficient and quality bone tissue around itself before its properties are diminished and the implant itself decomposes. The surfaces of metal based implants are highly reactive in biological systems and a number of reactions are observed at the implant-bone interface that can determine the stability of the implant and quality of osseous regeneration.
Some of the important factors that facilitate optimum osseointegration include physicochemical properties of the material surface, bioactivity of alloying elements, rate and kinetics of implant degradation, and the type of interaction between implant material and surrounding tissues.

Our work has mainly focused on studying the stability of four different $\mathrm{Mg}$ alloys, containing different quantities

Table 3 Blood cell count of control and experimental animals 3 months after implantation

\begin{tabular}{|c|c|c|c|c|c|c|c|c|}
\hline$\overline{\text { SI no }}$ & Agent & Unit & Control & Mg-5Zr & Mg-5Zr-Ca & Mg-2Zr-5Sr & $\mathrm{Mg}-\mathrm{Zr}-2 \mathrm{Sr}$ & Range \\
\hline $\mathrm{I}$ & WBC & $10^{3} / \mathrm{mL}$ & $9.03 \pm 2.07$ & $7.07 \pm 0.38$ & $6.16 \pm 2.50$ & $7.63 \pm 2.47$ & $10.52 \pm 1.69$ & $5.1-9.7$ \\
\hline 2 & LYM & $\%$ & $77.15 \pm 16.00$ & $77.03 \pm 1.39$ & $27.25 \pm 1.34$ & $87.20 \pm 5.49$ & $57.62 \pm 17.05$ & $39-68$ \\
\hline 3 & RBC & $10^{6} / \mathrm{mL}$ & $5.92 \pm 0.28$ & $6.50 \pm 0.16$ & $5.52 \pm 0.35$ & $6.03 \pm 0.46$ & $4.76 \pm 0.75$ & $5.3-6.8$ \\
\hline 4 & HGB & $\mathrm{g} / \mathrm{dL}$ & $12.98 \pm 1.15$ & $14.27 \pm 0.46$ & $12.18 \pm 0.69$ & $10.80 \pm 2.19$ & $11.18 \pm 2.56$ & $9.8-14.0$ \\
\hline 5 & HCT & $\%$ & $40.38 \pm 0.54$ & $50.37 \pm 1.33$ & $35 \pm 3.25$ & $45.53 \pm 1.42$ & $35.20 \pm 2.02$ & $34-43$ \\
\hline 6 & MCV & $\mathrm{fL}$ & $68.43 \pm 4.20$ & $77.53 \pm 0.15$ & $63.45 \pm 1.87$ & $75.77 \pm 3.63$ & $75.21 \pm 10.49$ & $60-69$ \\
\hline 7 & $\mathrm{MCH}$ & $\mathrm{pg}$ & $21.88 \pm 0.87$ & $21.90 \pm 1.05$ & $22.01 \pm 0.16$ & $18.23 \pm 3.74$ & $23.27 \pm 2.17$ & $20-23$ \\
\hline 8 & $\mathrm{MCHC}$ & $\mathrm{g} / \mathrm{dL}$ & $32.15 \pm 3.28$ & $28.30 \pm 1.45$ & $34.80 \pm 1.27$ & $24.07 \pm 4.39$ & $31.54 \pm 5.97$ & $31-35$ \\
\hline 9 & PLT & $10^{3} / \mathrm{mL}$ & $418.67 \pm 237.59$ & $472.33 \pm 160.38$ & $1219.50 \pm 104.16$ & $479.00 \pm 224.53$ & $1085.28 \pm 3|6.5|$ & $158-650$ \\
\hline
\end{tabular}

Abbreviations: HCT, hematocrit; HGB, hemoglobin; LYM, lymphocytes; MCH, mean corpuscular hemoglobin; MCHC, mean corpuscular hemoglobin concentration; MCV, mean corpuscular volume; PLT, platelet; RBC, red blood cells; WBC, white blood cells; Mg, magnesium; Zr, zirconium; Ca, calcium; Sr, strontium. 
Table 4 Values of serum biochemical parameters of control and experimental animals after 3 months implantation

\begin{tabular}{|c|c|c|c|c|c|c|}
\hline Parameters & Control & $M g-5 Z r$ & $\mathrm{Mg}-5 \mathrm{Zr}-\mathrm{Ca}$ & $\mathrm{Mg}-2 \mathrm{Zr}-5 \mathrm{Sr}$ & $\mathrm{Mg}-\mathrm{Zr}-2 \mathrm{Sr}$ & $\begin{array}{l}\text { Recommended } \\
\text { level }\end{array}$ \\
\hline Liver functions & & & $49.51 \pm 9.736$ & & $25.17 \pm 1.914$ & \\
\hline Urea (mg/dL) & $24.91 \pm 2.186$ & $35.68 \pm 8.426$ & & $22.83 \pm 4.173$ & & $5.00-25.00$ \\
\hline Uric acid (mg/dL) & $0.76 \pm 0.016$ & $0.82 \pm 0.185$ & $0.69 \pm 0.084$ & $1.59 \pm 0.634$ & $1.13 \pm 0.559$ & $1.0-4.3$ \\
\hline Creatinine (mg/dL) & $1.03 \pm 0.046$ & $1.23 \pm 0.195$ & & $0.76 \pm 0.062$ & & $0.5-2.6$ \\
\hline \multirow[t]{2}{*}{ Kidney functions } & & & $1.39 \pm 0.126$ & & $1.27 \pm 0.369$ & \\
\hline & & & $61.50 \pm 10.136$ & & $|9.92 \pm 9.58|$ & \\
\hline SGOT (U/L) & $22.48 \pm 2.410$ & $19.18 \pm 2.333$ & & $31.29 \pm 3.358$ & & $10.0-86.0$ \\
\hline SGPT (U/L) & $28.20 \pm 2.870$ & $37.78 \pm 1.333$ & $65.42 \pm 16.494$ & $37.57 \pm 10.667$ & $43.79 \pm 2.822$ & $20.0-120.0$ \\
\hline ALP (U/L) & $116.02 \pm 9.770$ & $|25.80 \pm 2.92|$ & $105.13 \pm 27.555$ & $89.62 \pm 1.324$ & $105.81 \pm 0.584$ & $25.0-65.0$ \\
\hline Total protein $(\mathrm{g} / \mathrm{dL})$ & $4.30 \pm 0.470$ & $6.52 \pm 3.344$ & $3.40 \pm 0.301$ & $5.16 \pm 0.026$ & $8.42 \pm 0.888$ & $5.0-7.5$ \\
\hline \multicolumn{7}{|l|}{ Electrolytes } \\
\hline Magnesium (mmol/L) & $2.50 \pm 0.138$ & $2.36 \pm 0.534$ & $2.21 \pm 0.385$ & $2.61 \pm 0.019$ & $2.51 \pm 0.387$ & $2.0-5.4$ \\
\hline Calcium (mg/dL) & $15.95 \pm 0.759$ & $17.95 \pm 0.002$ & $18.69 \pm 1.297$ & $14.85 \pm 2.589$ & $16.75 \pm 0.059$ & $5.6-12.1$ \\
\hline Chloride (mmol/L) & $95.08 \pm|2.37|$ & $95.61 \pm 22.144$ & $91.65 \pm 4.134$ & || $7.48 \pm 4.6 \mid 4$ & $|05.73 \pm 2.68|$ & $92.0-120.0$ \\
\hline
\end{tabular}

Abbreviations: ALP, alkaline phosphatase; SGOT, serum glutamic oxaloacetic transaminase; SGPT, serum glutamic pyruvate transaminase; Ca, calcium; Mg, magnesium; $\mathrm{Zr}$, zirconium; Sr, strontium.

of $\mathrm{Zr}$, Sr, and $\mathrm{Ca}$ and correlating the surface energy of each alloy to its capacity for osteoinduction and integration at the implant site in rabbit femur bones. Based on our results, we have demonstrated that $\mathrm{Mg}$ with $\mathrm{Zr}$-Sr alloys ( $\mathrm{Mg}-2 \mathrm{Zr}-5 \mathrm{Sr}$ and $\mathrm{Mg}-\mathrm{Zr}-2 \mathrm{Sr}$ ) are superior biomaterials for orthopedic applications than are alloys that contain only $\mathrm{Zr}$ or a combination of $\mathrm{Zr}$ and $\mathrm{Ca}$. It can be seen from the XRD data in Figure 1 ( $\mathrm{Mg}-2 \mathrm{Zr}-5 \mathrm{Sr}$ and $\mathrm{Mg}-\mathrm{Zr}-2 \mathrm{Sr}$ ) that there is a formation of $\mathrm{Mg}_{17} \mathrm{Sr}_{2}$ intermediate phase in Sr-containing alloys. $\mathrm{Mg}_{17} \mathrm{Sr}_{2}$ is reported to be the most $\mathrm{Mg}$-rich stable compound in the $\mathrm{Mg}-\mathrm{Sr}$ system,${ }^{36}$ which can improve the corrosion resistance of $\mathrm{Mg}$ based alloys. Inclusion of $\mathrm{Zr}$ in $\mathrm{Mg}$ alloys acts as a grain refining agent, which causes strengthening of the alloy by formation of $\alpha-Z r$ phases and grain boundary strengthening. ${ }^{37}$ In our study, only $\mathrm{Ca}$ or $\mathrm{Zr}$ containing alloys ( $\mathrm{Mg}-5 \mathrm{Zr}$ and $\mathrm{Mg}-5 \mathrm{Zr}-\mathrm{Ca}$ ) were more unstable, and upon degradation in vivo, they showed an abundance of residual alloy material at the implant site (Figures 3 and 4). This has not been reported earlier because the stability of Ca-containing $\mathrm{Mg}$ alloys has been studied only in the absence of $\mathrm{Zr},{ }^{38-41}$ and Mg alloys containing only $\mathrm{Zr}$ have not been reported so far. The elemental constitution of the alloying metals also affects the properties of newly induced bone, as several charged groups $\left(\mathrm{O}, \mathrm{OH}^{-}\right.$, etc) on the alloy surface contribute to the overall electronegativity of the implant material. ${ }^{42}$ In a recent report using titanium based implants, it has been shown that in addition to the electronegativity of the implant surface, several other factors can also influence the osteoinduction process in vivo. ${ }^{43}$ The advantages and limitations of individual alloying metals have also been described in our previous report, ${ }^{28}$ where we had shown that alloying processes improved the mechanical strength of implant materials and made their properties similar to those of bone tissue. Based upon these criteria, we can conclude from our results that $\mathrm{Mg}-5 \mathrm{Zr}-\mathrm{Ca}$ implant, which showed high compressive strength, was not suitable for osteointegration, whereas $\mathrm{Mg}-2 \mathrm{Zr}-5 \mathrm{Sr}$ and $\mathrm{Mg}-\mathrm{Zr}-2 \mathrm{Sr}$ implants, tend to resemble natural bone in their properties due to decreased compressive strength.

For assessment of bone formation in vivo, the two most important properties of implant-induced NB tissue are osteoinduction and osteointegration. These two processes were evaluated by histological and immunohistochemical staining of peri-implant bone sections. In contact osteogenesis, the NB formation occurs on the surface of the implant itself. The osteoblasts secrete a collagen-rich bone matrix directly on the implant surface as they differentiate into osteocytes. In later stages, the matrix is mineralized as calcified collagen, and a matrix free area separates the old bone from the NB. ${ }^{44} \mathrm{In}$ distance osteogenesis, NB is formed over the old bone surface, and the differentiating osteoblasts/osteocytes and the secreted matrix are all seen in close association with the surface of the old bone. Due to this pattern of cells and bone matrix, a space is generated between the NB and the implant surface, which becomes occupied with dying or undifferentiated osteoblast that are unable to migrate from the bone surface. ${ }^{44}$ As mentioned earlier $\mathrm{Mg}-2 \mathrm{Zr}-5 \mathrm{Sr}$ alloy- and $\mathrm{Mg}-\mathrm{Zr}-2 \mathrm{Sr}$ alloy-induced NB exhibited contact osteogenesis, whereas Mg-5Zr- and Mg-5Zr-Ca-induced NB had distance osteogenesis properties, which are highlighted in the H\&E staining patterns shown in Figure 3. In addition, the presence of differentiated osteoclasts, which is indicative of better bone resorption activity in $\mathrm{Mg}-2 \mathrm{Zr}-5 \mathrm{Sr}-$ and $\mathrm{Mg}-\mathrm{Zr}-2 \mathrm{Sr}$-induced bones (Figure 4), 
suggested that the quality of bone tissue around these implants was superior to the other bone types. In contrast, we observed hyperactivity of osteoclasts in $\mathrm{Mg}-5 \mathrm{Zr}-\mathrm{Ca}$-induced bones, which led to deformed and weaker bone tissue.

The facilitation of bone formation around the Mg-based implants is associated with the release of free $\mathrm{Mg}^{2+}$ ions during the biodegradation process, which can contribute to enhanced activity of osteoblasts and a consequent increase in ECM quantity in the peri-implant bone. In our study, we analyzed this activity by Col immunostaining and MT staining. Collagen type-I is an important marker of osteogenesis, ${ }^{45}$ and we could observe this in $\mathrm{Mg}-2 \mathrm{Zr}-5 \mathrm{Sr}-$ and $\mathrm{Mg}-\mathrm{Zr}-2 \mathrm{Sr}-$ induced bones (Figure 5). The extent of mineralization is shown by deep blue staining of MT and the DXA results (Figure 7A and $\mathrm{B}$ ). The blue stained sections distinguish the mineralized and nonmineralized ECM, and DXA measurements of BMC and BMD suggested bone growth and mineral accumulation in and around the implant site. Most of the components of bone accumulation that are associated with change in bone size are detected as bone mass and bone density. Our results show good BMC and BMD for the implanted femur bones, which are in line with the results of histology and immunohistochemical studies. Further, the impact on bone formation can be determined based on blood and serum biochemical analysis. The elevated blood platelet numbers in $\mathrm{Mg}-\mathrm{Zr}-2 \mathrm{Sr}$ in the third month (Table 3 ) indicates platelet activation, which can make cells aggregate and form a clot. Stable clot formation is required for secretion of biochemical components for osteoconduction. ${ }^{46}$ We have reported the blood cell counts obtained at 3 months postsurgery, which is a lengthy time period for the cells to come back to their normal level, even if there happens to be any kind of alterations in their values during the early time period postsurgery. It could also be reasoned that an inflammatory response has occurred and returned to baseline by 3 months. Nevertheless, the alloys showed no inflammatory response or side effects by the specified time period of study and, hence, can be a suitable biodegradable implant material.

The surface energy and wettability of the implant material are significant in determining cell-biomaterial interactions, and they significantly influences biological events at the subcellular and cellular level (eg, protein adsorption, cell attachment and spreading, etc). ${ }^{47}$ In our study, $\mathrm{Mg}-\mathrm{Zr}-2 \mathrm{Sr}$ alloy exhibited lowest surface energy, which could be attributed to lower weight percent of $\mathrm{Zr}$ and $\mathrm{Sr}(1 \%$ and $2 \% \mathrm{wt}$, respectively) and, hence, more availability of free $\mathrm{Mg}^{2+}$ ions in the vicinity of this alloy. Further, lower surface energy levels of Sr-containing $\mathrm{Mg}-2 \mathrm{Zr}-5 \mathrm{Sr}$ and $\mathrm{Mg}-\mathrm{Zr}-2 \mathrm{Sr}$ alloys in comparison to $\mathrm{Mg}-5 \mathrm{Zr}$ and $\mathrm{Mg}-5 \mathrm{Zr}-\mathrm{Ca}$ alloy surfaces signifies the role of $\mathrm{Sr}$ in controlling the surface energy levels of these alloys. Since $\mathrm{Mg}-2 \mathrm{Zr}-5 \mathrm{Sr}$ and $\mathrm{Mg}-\mathrm{Zr}-2 \mathrm{Sr}$ alloy-induced NB tissues exhibited contact osteogenesis properties, whereas $\mathrm{Mg}-5 \mathrm{Zr}$ and $\mathrm{Mg}-5 \mathrm{Zr}-\mathrm{Ca}$ alloy-induced bone tissues showed distance osteogenesis properties, it can be predicted that Sr-containing Mg-Zr alloys with lower surface energy could induce better bone formation in vivo than high surface energy containing Sr-deficient Mg-Zr alloys.

The surface integrity of the alloys determine the rate and extent of bone formation, osseointegration, and osteoconduction. In vivo evaluation becomes necessary to understand how the implant will perform in a physiological environment. Various physicochemical factors can play equally important roles in new bone induction, ${ }^{43}$ therefore, no single property should be considered as the only criterion for selecting an implant material for orthopedic application. Our study highlights the importance of including $\mathrm{Sr}$ and excluding $\mathrm{Ca}$ in optimal combinations of $\mathrm{Mg}-\mathrm{Zr}$ alloys to obtain good osteogenic outcome in rabbit bones.

The clinical significance of our study undoubtedly lies in alloying Sr with Mg-Zr-based biodegradable alloys and that $2 \%$ wt of Sr alloying in $\mathrm{Mg}$-Zr system can improve the bone remodeling rate in vivo. Although we have used a total of 30 animals for the in vivo experiments, more detailed investigation on bone formation on the $\mathrm{Mg}-\mathrm{Zr}-\mathrm{Sr} / \mathrm{Ca}$ implants in a cohort animal study would be needed before the implants can proceed to clinical trial. Also, supplemental in vivo investigations on larger animal models is required to determine the efficacy of the $\mathrm{Mg}$ alloy system under more complex biological conditions. Nonetheless, $\mathrm{Mg}-\mathrm{Zr}$ alloys containing $\mathrm{Sr}$ as a complementary bivalent cation in optimum quantities can be used to promote efficient osseointegration for orthopedic implant applications.

\section{Conclusion}

In this paper we have studied a new class of biocompatible and biodegradable implants that are made of $\mathrm{Mg}$ as a base alloy and contain varying quantities of $\mathrm{Zr}, \mathrm{Sr}$, and $\mathrm{Ca}$. Some basic physicochemical properties of these alloys have been described earlier. ${ }^{2}$ Here we have estimated the surface energy of the alloys by measuring the contact angle of polar solvents on the alloy surface and correlated it with their bone forming capacity in the peri-implant area by histological and radiological evaluation. Our major findings are as follows:

1. It was found through our physicochemical investigations that inclusion of $\mathrm{Sr}$ into the $\mathrm{Mg}-\mathrm{Zr}$ alloy increases both the corrosion resistance and stability of these alloys. Presence of $\mathrm{Sr}$ led to the formation of $\mathrm{Mg}_{17} \mathrm{Sr}_{2}$ 
intermediate phase that strengthens the alloy in a Mg-rich system. Upon addition of $\mathrm{Sr}$, the compressive strength of these alloys resemble more closely natural bone.

2. Our results show that optimal contents of $\mathrm{Zr}$ and $\mathrm{Sr}$ increase the surface energy of the alloys and their capacity to simulate contact osteogenesis in the peri-implant area.

3. We have also shown that inclusion of $\mathrm{Ca}$ without $\mathrm{Sr}$ reduces the surface energy on the alloy surface and decreases its bone-inducing activity.

4. The osteogenesis, osteoinduction, and osseointegration of Sr-containing alloys could be seen by mineral and trabecular bone formation on the implant surface. Further, the DXA and blood and serum biochemical measurements prove that the bone growth and mineral accumulation on the implant surface is best for the Srcontaining alloy.

5. The pattern of contact osteogenesis remained the same in both the Sr-containing Mg alloys; however, the higher concentration of $\mathrm{Sr}(5 \% \mathrm{wt})$ gave a greater level of bone formation. This was probably due to the presence of higher amount of secondary phase, which promoted more uncontrolled growth of osteoblast cells in vivo as compared to the lower concentration ( $2 \% \mathrm{wt}$ ) as seen by histological and immunohistochemical studies of these alloys.

6. Although more detailed in vivo studies are required to confirm the superior bone healing capacity of $\mathrm{Sr}$, the present results indicate that $\mathrm{Sr}$ in $\mathrm{Mg}$-based alloys notably increases early bone apposition in rabbit cancellous bones and that $2 \% \mathrm{wt} \mathrm{Sr}$ is the optimum concentration for $\mathrm{Mg}-\mathrm{Zr}-\mathrm{Sr}$ alloys to elicit the best osseointegration. Further, it also helps in complete degradation of the implant within the specified period of surgery.

In the future, our results can guide the formulation of more efficient biodegradable alloys for orthopedic applications.

\section{Acknowledgments}

The authors acknowledge the financial support from the Department of Biotechnology (DBT), Government of India, New Delhi GAP 0311 to GP and a grant from the Australia-India Strategic Research Fund (AISRF) BF030031 to CW and PH. The authors thank the technical staff members of CCMB Animal House for their excellent technical support and co-operation throughout the experimental period.

\section{Disclosure}

The authors report no conflicts of interest in this work.

\section{References}

1. Staiger MP, Pietak AM, Huadmai J, Dias G. Magnesium and its alloys as orthopedic biomaterials: a review. Biomaterials. 2006;27(9): 1728-1734.

2. Witte F. The history of biodegradable magnesium implants: a review. Acta Biomater. 2010;6(5):1680-1692.

3. Denkena B, Witte F, Podolsky C, Lucas A. Degradable implants made of magnesium alloys. In: Proceedings of the 5th euspen International Conference; Montpellier, France; May 8-12, 2005:735-738.

4. Caneva M, Botticelli D, Stellini E, Souza SL, Salata LA, Lang NP. Magnesium-enriched hydroxyapetite at immediate implants: a histomorphometric study in dogs. Clin Oral Implants Res. 2011;22(5): 512-517.

5. Crespi R, Capparè P, Gherlone E. Magnesium-enriched hydroxyapetite compared to calcium sulfate in the healing of human extraction sockets: radiographic and histomorphometric evaluation at 3 months. J Periodontol. 2009;80(2):210-218.

6. Araújo M, Linder E, Wennström J, Lindhe J. The influence of Bio-Oss collagen on healing of an extraction socket: an experimental study in the dog. Int J Periodontics Restorative Dent. 2008;28(2):123-135.

7. Araújo MG, Lindhe J. Ridge preservation with the use of Bio-Oss collagen: A 6-month study in the dog. Clin Oral Implants Res. 2009;20(5): 433-440.

8. Witte F, Ulrich H, Rudert M, Willbold E. Biodegradable magnesium scaffolds: Part 1: appropriate inflammatory response. J Biomed Mater Res A. 2007;81(3):748-756.

9. He YH, Tao HR, Zhang Y, et al. Biocompatibility of bio-Mg-Zn alloy within bone with heart, liver, kidney and spleen. Chinese Science Bulletin. 2009;54(3):484-491.

10. Kraus T, Fischerauer SF, Hänzi AC, Uggowitzer PJ, Löffler JF, Weinberg AM. Magnesium alloys for temporary implants in osteosynthesis: in vivo studies of their degradation and interaction with bone. Acta Biomater. 2012;8(3):1230-1238.

11. Xin Y, Jiang J, Huo K, Tang G, Tian X, Chu PK. Corrosion resistance and cytocompatibility of biodegradable surgical magnesium alloy coated with hydrogenated amorphous silicon. J Biomed Mater Res A. 2009;89(3):717-726.

12. Williams DF. On the mechanisms of biocompatibility. Biomaterials. 2008;29(20):2941-2953.

13. Castellani C, Lindtner RA, Hausbrandt $P$, et al. Bone-implant interface strength and osseointegration: biodegradable magnesium alloy versus standard titanium control. Acta Biomater. 2011;7(1):432-440.

14. Ducheyne PL, Hasting GW. Functional behaviour of orthopedic biomaterials applications. Boca Raton, FL: CRC Press; 1984;(2):3.

15. López HY, Cortés-Hernández DA, Escobedo S, Mantovani D. In vitro bioactivity assessment of metallic magnesium. Key Eng Mater. 2006; 309-311:453-456.

16. Witte F, Hort N, Vogt C, et al. Degradable biomaterials based on magnesium corrosion. Curr Opin Solid State Mater Sci. 2008; 12(5-6):63-72.

17. Janning C, Willbold E, Vogt C, et al. Magnesium hydroxide temporarily enhancing osteoblast activity and decreasing the osteoclast number in peri-implant bone remodelling. Acta Biomater. 2010;6(5): 1861-1868.

18. Gu XN, Xie XH, Li N, Zheng YF, Qin L. In vitro and in vivo studies on a Mg-Sr binary alloy system developed as a new kind of biodegradable metal. Acta Biomater. 2012;8(6):2360-2374.

19. Aghion E, Levy G, Ovadia S. In vivo behavior of biodegrardable Mg-Nd-Y-Zr-Ca alloy. J Mater Sci Mater Med. 2012;23(3):805-812.

20. Park RS, Kim YK, Lee SJ, et al. Corrosion behaviour and cytotoxicity of Mg-35Zn-3Ca alloy for surface modified biodegradable implant material. J Biomed Mater Res B Appl Biomater. 2012;100(4): 911-923.

21. Huehnerschulte TA, Reifenrath J, von Rechenberg B, et al. In vivo assessment of the host reactions to the biodegradation of the two novel magnesium alloys ZEK100 and AX30 in an animal model. Biomed Eng Online. 2012;11:14. 
22. Zhang E, Xu L, Yu G, Pan F, Yang K. In vivo evaluation of biodegradable magnesium alloy bone implant in the first 6 months implantation. J Biomed Mater Res A. 2009;90(3):882-893.

23. Wang H, Guan S, Wang Y, et al. In vivo degradation behavior of Cadeficient hydroxyapetite coated $\mathrm{Mg}-\mathrm{Zn}-\mathrm{Ca}$ alloy for bone implant application. Colloids Surf B Biointerfaces. 2011;88(1):254-259.

24. Depprich R, Zipprich H, Ommerborn M, et al. Osseointegration of zirconia implants: an SEM observation of the bone-implant interface. Head Face Med. 2008;4:25.

25. Dziuba D, Meyer-Lindenberg A, Seitz JM, Waizy H, Angrisani N, Reifenrath J. Long-term in vivo degradation behaviour and biocompatibility of the magnesium alloy ZEK100 for use as a biodegradable bone implant. Acta Biomater. Epub August 28, 2012.

26. Steven IR, Graf CN, Hopkinson WJ, Hallab NJ. Immune response to implants [webpage on the Internet]. Medscape Reference; 2011 Apr. Available from: http://emedicine.medscape.com/article/1230696.

27. Yun YH, Dong Z, Lee N, et al. Revolutionizing biodegradable metals. Materials Today. 2009;12(10):22-32.

28. Li Y, Wen C, Mushahary D, et al. Mg-Zr-Sr alloys for biodegradable implant materials. Acta Biomater. 2012;8(8):3177-3188.

29. Sista S, Wen C, Hodgson PD, Pande G. The influence of surface energy of titanium-zirconium alloy on osteoblast cell functions in vitro. J Biomed Mater Res A. 2011;97A(1):27-36.

30. Owens DK, Wendt RC. Estimation of the surface free energy of polymers. J Appl Polym Sci. 1969;13(8):1741-1749.

31. Luna LG. Manual of Histologic Staining Methods of the Armed Forces Institute of Pathology. 3rd ed. New York, NY: Blakiston Division, McGraw-Hill; 1968.

32. Mayer I, Schlam R, Featherstone JD. Magnesium-containing carbonate apatites. J Inorg Biochem. 1997;66(1):1-6.

33. Park JW, Kim YJ, Jang JH, Song H. Osteoblast response to magnesium ion-incorporated nanoporous titanium oxide surfaces. Clin Oral implants Res. 2010;21(11):1278-1287.

34. Lim JY, Shaughnessy MC, Zhou Z, Noh H, Vogler EA, Donahue HJ. Surface energy effects on osteoblast spatial growth and mineralization. Biomaterials. 2008;29(12):1776-1784.

35. Lynch MP, Stein JL, Stein GS, Lian JB. The influence of type I collagen on development and maintenance of the osteoblast phenotype in primary and passaged rat calvarial osteoblasts: modification of expression of genes supporting cell growth, adhesion, and extracellular matrix mineralization. Exp Cell Res. 1995;216(1):35-45.
36. Gu XN, Xie XH, Li N, Zheng YF, Qin L. In vitro and in vivo studies on a Mg-Sr binary alloy system developed as a new kind of biodegradable metal. Acta Biomater. 2012;8(6):2360-2374.

37. Song G, St John D. The effect of zirconium grain refinement on the corrosion behaviour of magnesium-rare earth alloy MEZ. J Light Metals. 2002;2(1):1-16.

38. Wang $\mathrm{H}$, Guan S, Wang Y, et al. In vivo degradation behavior of Ca-deficient hydroxyapatite coated $\mathrm{Mg}-\mathrm{Zn}-\mathrm{Ca}$ alloy for bone implant application. Colloids Surf B Biointerfaces. 2011;88(1):254-259.

39. Rosalbino F, De Negri S, Saccone A, Angelini E, Delfino S. Bio-corrosion characterization of $\mathrm{Mg}-\mathrm{Zn}-\mathrm{X}(\mathrm{X}=\mathrm{Ca}, \mathrm{Mn}, \mathrm{Si})$ alloys for biomedical applications. J Mater Sci Mater Med. 2010;21(4):1091-1098.

40. Li Z, Gu X, Lou S, Zheng Y. The development of binary Mg-Ca alloys for use as biodegradable materials within bone. Biomaterials. 2008;29(10):1329-1344.

41. Berglund IS, Brar HS, Dolgova N, et al. Synthesis and characterization of Mg-Ca-Sr alloys for biodegradable orthopedic implant applications. J Biomed Mater Res B Appl Biomater. 2012;100(6):1524-1534.

42. Dhayal M, Kapoor R, Sistla PG, et al. Growth, differentiation, and migration of osteoblasts on transparent $\mathrm{Ni}$ doped $\mathrm{TiO}_{2}$ thin films deposited on borosilicate glass. J Biomed Mater Res A. 2012;100(5):1168-1178.

43. Saulacic N, Bosshardt DD, Bornstein MM, Berner S, Buser D. Bone apposition to a titanium-zirconium alloy implant, as compared to two other titanium-containing implants. Eur Cell Mater. 2012;23:273-288; discussion 286-288.

44. Davies JE. Understanding peri-implant endosseous healing. J Dent Educ. 2003;67(8):932-949.

45. Cooper LF, Handelman B, McCormack SM, Guckes AD. Binding of murine osteoblastic cells to titanium disks and collagen I gels: implications for alternative interpretations of osseointegration. Int $J$ Oral Maxillofac Implants. 1993;8(3):264-272.

46. Baier RE. The role of surface energy in thrombogenesis. Bull NYAcad Med. 1972;48(2):257-272.

47. Allen LT, Tosetto M, Miller IS, et al. Surface-induced changes in protein adsorption and implications for cellular phenotypic responses to surface interaction. Biomaterials. 2006;27(16):3096-3108. 


\section{Supplementary figures}
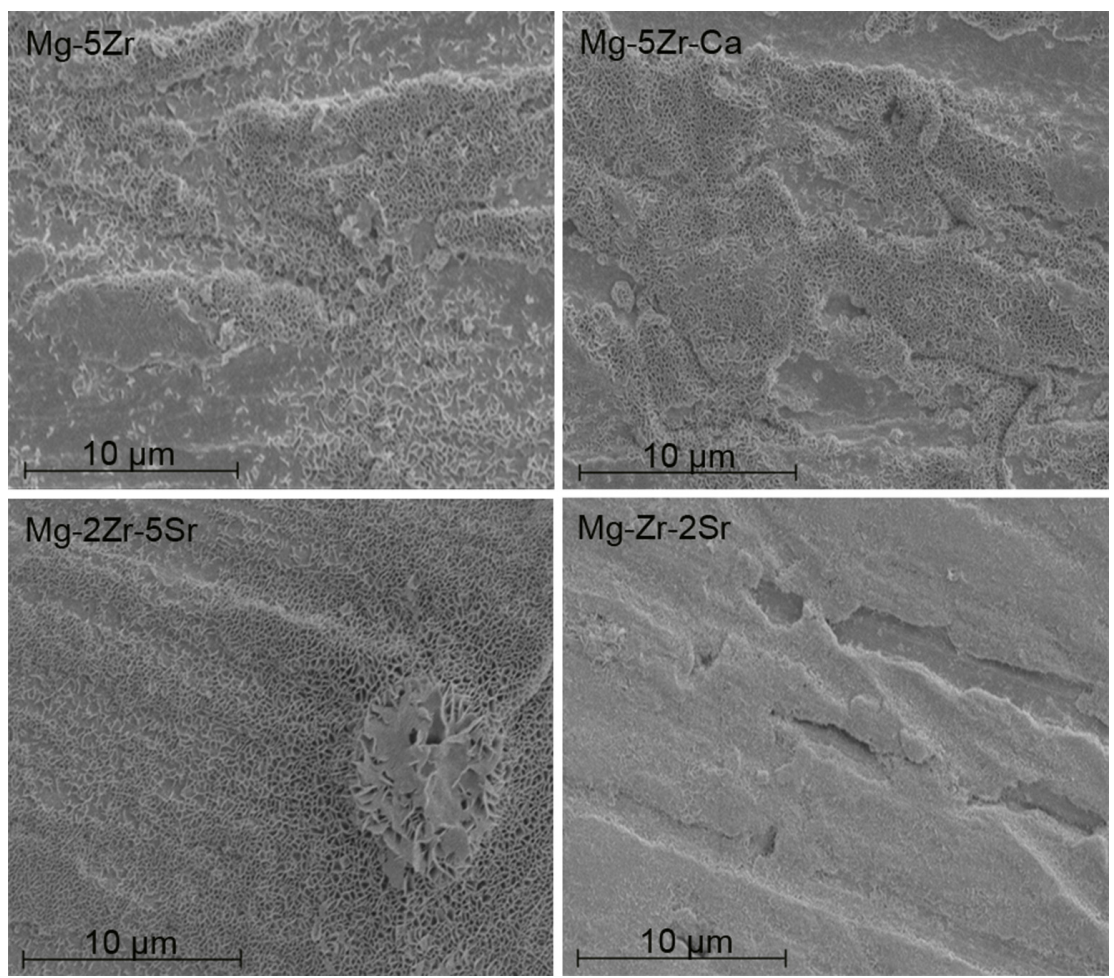

Figure SI Scanning electron micrographs of magnesium alloys before incubation in the culture media. Abbreviations: $\mathrm{Ca}$, calcium; $\mathrm{Mg}$, magnesium; $\mathrm{Zr}$, zirconium; $\mathrm{Sr}$, strontium.
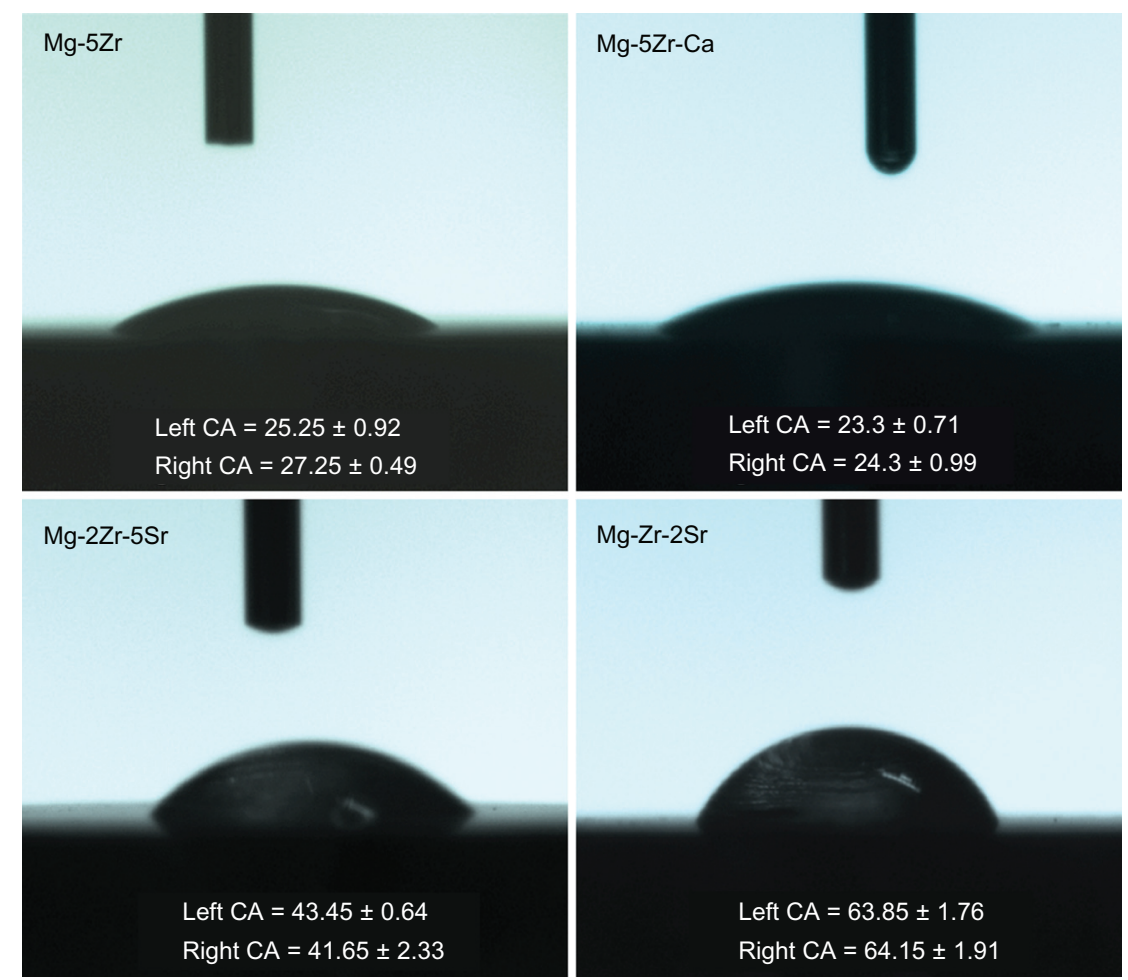

Figure S2 Representative figures of contact angles of the four magnesium alloys used for calculating surface energy.

Note: The contact angles (CA) were determined using water and measured within 60 seconds of the droplet release from the syringe probe. Abbreviations: $\mathrm{Ca}$, calcium; $\mathrm{Mg}$, magnesium; $\mathrm{Zr}$, zirconium; $\mathrm{Sr}$, strontium. 

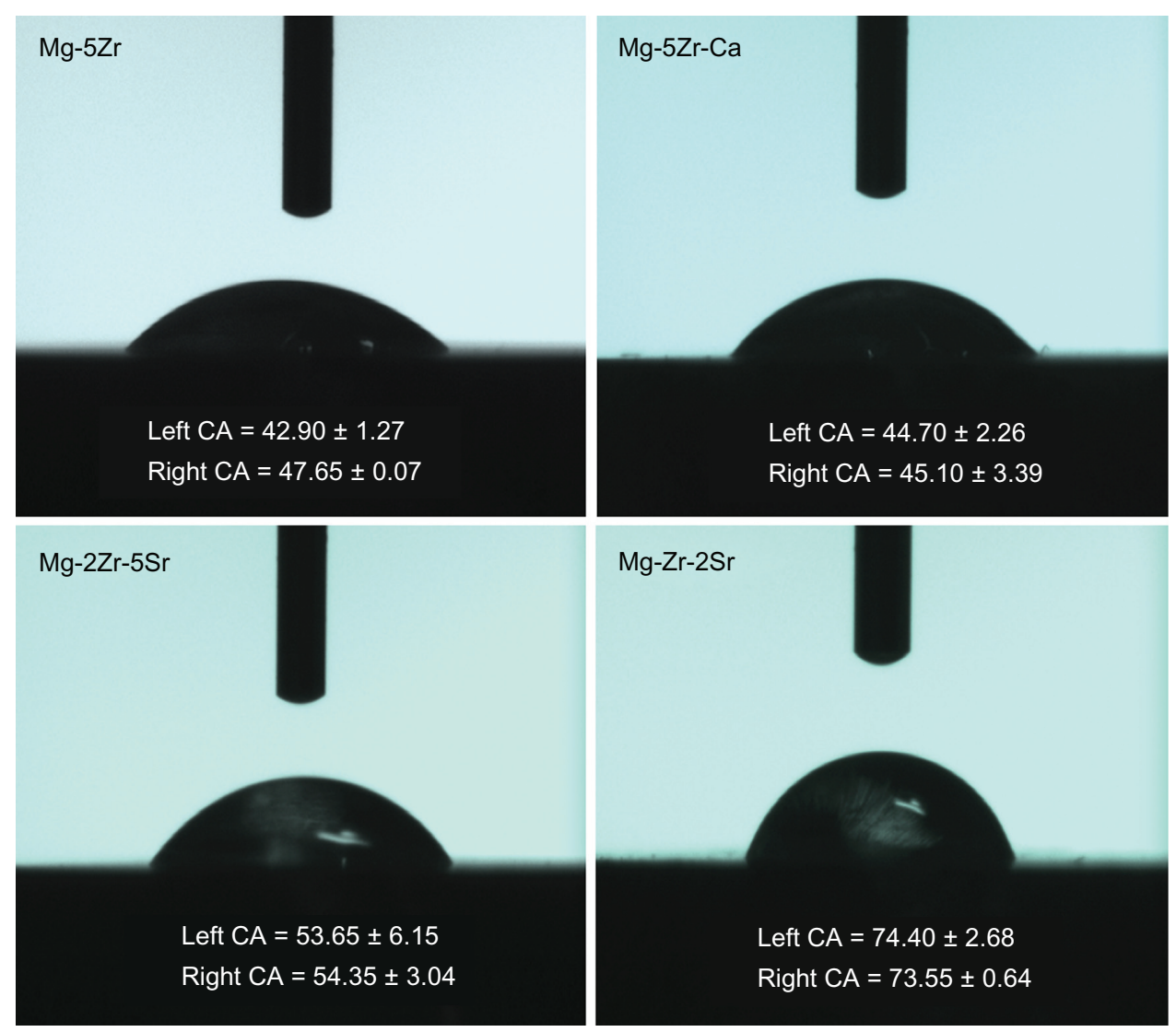

Figure S3 Representative figures of contact angles of the four magnesium-based alloys used for calculating surface energy.

Note: The contact angles (CA) were determined using glycerol and measured within 60 seconds of the droplet release from the syringe probe. Abbreviations: $\mathrm{Ca}$, calcium; $\mathrm{Mg}$, magnesium; $\mathrm{Zr}$, zirconium; Sr, strontium.

\section{Publish your work in this journal}

The International Journal of Nanomedicine is an international, peerreviewed journal focusing on the application of nanotechnology in diagnostics, therapeutics, and drug delivery systems throughout the biomedical field. This journal is indexed on PubMed Central, MedLine, CAS, SciSearch $\AA$, Current Contents ${ }^{\circledR} /$ Clinical Medicine,
Journal Citation Reports/Science Edition, EMBase, Scopus and the Elsevier Bibliographic databases. The manuscript management system is completely online and includes a very quick and fair peer-review system, which is all easy to use. Visit http://www.dovepress.com/ testimonials.php to read real quotes from published authors.

Submit your manuscript here: http://www.dovepress.com/international-journal-of-nanomedicine-journal 